\title{
Evacuation Decision-Making in the 2016 Chimney Tops 2 Fire: Results of a Household Survey
}

Emily H. Walpole Erica D. Kuligowski

Lauren Cain Alicea Fitzpatrick Christin Salley

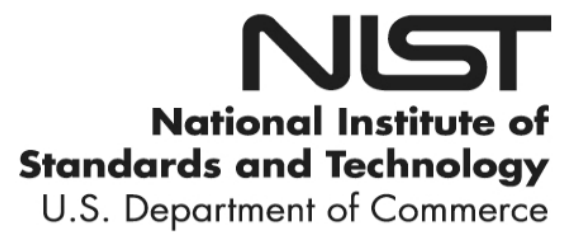


NIST Technical Note 2103

\section{Evacuation Decision-Making in the 2016 Chimney Tops 2 Fire: Results of a Household Survey}

Emily H. Walpole Erica D. Kuligowski

Lauren Cain

Alicea Fitzpatrick

Christin Salley

Fire Research Division

Engineering Laboratory

This publication is available free of charge from: https://doi.org/10.6028/NIST.TN.2103

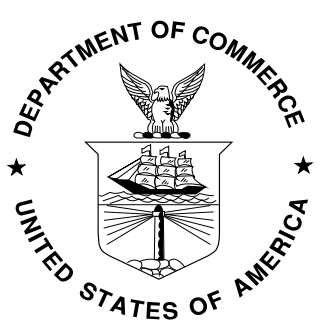

U.S. Department of Commerce

Wilbur L. Ross, Jr., Secretary 
Certain commercial entities, equipment, or materials may be identified in this document in order to describe an experimental procedure or concept adequately. Such identification is not intended to imply recommendation or endorsement by the National Institute of Standards and Technology, nor is it intended to imply that the entities, materials, or equipment are necessarily the best available for the purpose.

National Institute of Standards and Technology Technical Note 2103

Natl. Inst. Stand. Technol. Tech. Note 2103, 60 pages (July 2020) CODEN: NTNOEF

This publication is available free of charge from: https://doi.org/10.6028/NIST.TN.2103 


\begin{abstract}
To gain insight into the emergency communication and evacuation decision-making surrounding the 2016 Chimney Tops 2 fire, NIST conducted (via a small business survey research contractor) an online survey targeting homeowners in the Gatlinburg, TN area from October 2018 to May 2019. Among the 323 participants selected in our final sample, it was found that the majority were largely unaware of wildfire risks and had not experienced evacuations previously. On the day the fire spread into residential areas, only a small percentage reported receiving information from official sources or official evacuation notices, instead relying more commonly on information from the media, social contacts, and cues from the fire itself (such as smoke, embers, and flames) to become informed about the impending wildfire threat. The great majority of individuals evacuated from the area, most commonly on the day the fire spread into residential areas in response to intense fire cues and feeling afraid for themselves and others. A thematic analysis of voluntary end of survey comments provide additional nuance to these findings, in that many participants felt unprepared for the evacuation and took independent action to try to get themselves to safety.

Recommendations from these findings include the need for greater public outreach and awareness of local wildfire risks and preparation in the region, as well as what to expect in terms of evacuation procedures. In addition, these results highlight the importance of providing timely, coordinated, and clear official warning messages and signage to avoid chaotic or difficult evacuation processes. Specific recommendations on the construction of effective warning messages and limitations of the current work are provided.
\end{abstract}

\title{
Keywords:
}

Emergency communication; emergency management; evacuation; WUI; wildfire. 
Table of Contents

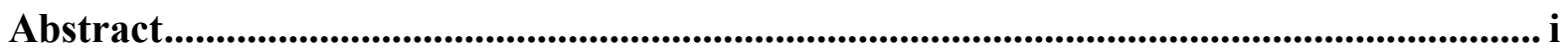

1. Introduction and Purpose ......................................................................................................... 1

1.1 Timeline of Fire Event .................................................................................. 2

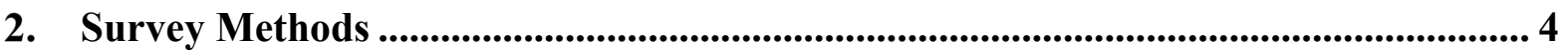

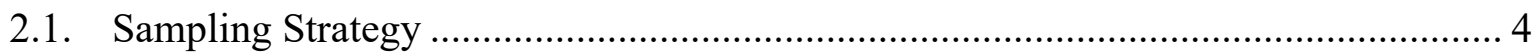

2.2. Final Study Sample ...................................................................................... 5

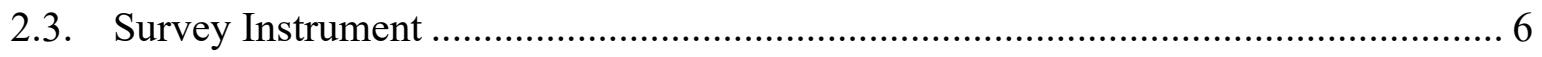

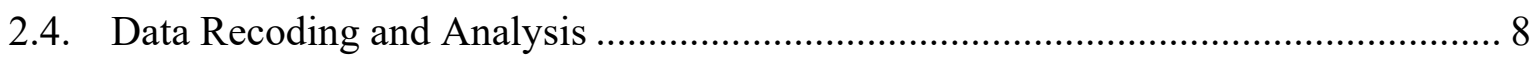

3. Descriptive Survey Results ....................................................................................9

3.1. Sociodemographic Characteristics of the Sample .............................................. 9

3.2. Pre-Event Factors: Fire Awareness and Preparation ........................................... 12

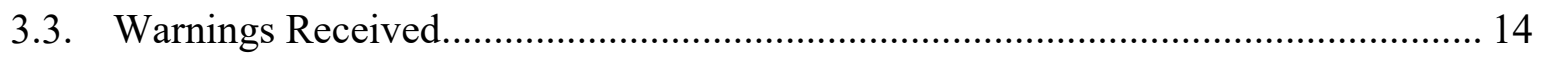

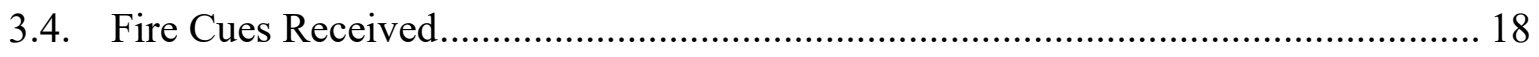

3.5. Evacuation Decision and Risk Perceptions ........................................................ 20

3.6. Evacuation Action and Main Rationales .............................................................. 24

4. Thematic Analysis of Survey Comments............................................................ 28

4.1. Theme 1 - Evacuation Information and Communication ................................... 28

4.2. Theme 2 - Evacuation Process............................................................................ 30

4.3. Theme 3 - Post-Event Impacts and Recovery ............................................... 32

4.4. Theme 4 - General Comments ............................................................................. 33

5. Summary of Findings and Recommendations ....................................................... 34

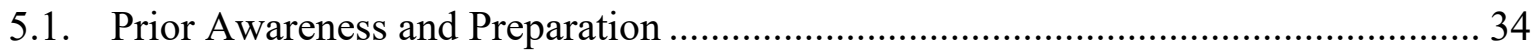

5.2. Warning Content, Timing, and Fire Cues .................................................... 35

5.3. Evacuation Decisions and Process .................................................................... 37

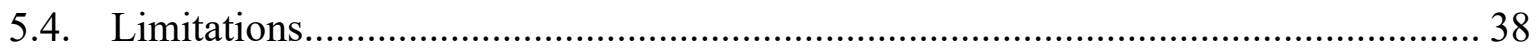

6. Conclusion .................................................................................................................... 39

7. References...................................................................................................................................... 40

APPENDIX A: Survey Instrument ...................................................................................... 42 


\section{Introduction and Purpose}

Many regions of the globe face increased wildfire threats due to environmental changes such as increased drought and warmer temperatures $[1,2]$. In particular, wildfires pose a threat to communities adjacent to or within forested areas, often referred to as the wildland-urban interface (WUI) ${ }^{1}$, which have expanded in recent decades due to their proximity to desirable natural amenities, among other factors $[3,4]$. The vulnerability of these growing populations to wildfires has increased scientific interest in which factors are associated with more positive and safe event outcomes, including when, how, and why individuals and households make the decision to evacuate to safety (or, conversely, choose to stay in place). A better understanding of these factors can inform more accurate evacuation planning and assist officials in improving warning and communication designs or traffic management during actual fire events.

A growing body of literature has examined various facets of evacuation decision-making, including qualitative work and modeling individual decision processes. From these studies we know that a variety of factors influence the decision to evacuate or stay, including personal values and the perceived efficacy of those protective actions [5, 6], risk perceptions of the fire event [6-8], and previous experience with or awareness of local wildfire threats [9]. In addition, the content and source of warning messages can have a significant influence on the likelihood of evacuation, including receiving messages from multiple sources [10] and official evacuation orders $[5,6,10]$. Environmental cues such as seeing others evacuating and sensing fire cues such as smoke and flames can also increase risk perceptions and motivation to evacuate $[5,8]$.

This technical note reports the results of a household survey of WUI community residents, focusing on their decision to evacuate from the 2016 Chimney Tops 2 (CT2) fire. This fire impacted the Gatlinburg, Tennessee area and led to the loss of 14 lives and the evacuation of some 14000 residents and tourists [11]. By better understanding the pre-event wildfire awareness, types of warnings and cues received, and evacuation decisions and experiences of these individuals, we hope to provide insights for improving future wildfire planning and response and to contribute case study findings to the growing body of work on individual wildfire preparation and response.

This report contains five sections. We will begin with a timeline and overview of the fire event itself (Section 1), and describe our survey sampling methods, instrument, and final sample selection (Section 2). We will then share in detail the descriptive results of the survey (Section 3; including sample characteristics, pre-event variables, warnings received, and evacuation decisions and rationale), as well as the results of a thematic analysis of end-ofsurvey comments (Section 4). We will conclude with a summary of results and associated recommendations resulting from this work and limitations of the research (Section 5).

\footnotetext{
${ }^{1}$ The term "wildland-urban interface" (or WUI) is being used here as a general term to refer to any area where houses are located in or near wildland vegetation and is not necessarily linked to a specific density of housing or wildlands.
} 


\subsection{Timeline of Fire Event}

The 2016 Chimney Tops 2 fire started in the Great Smoky Mountains National Park (GSMNP) outside of Gatlinburg, TN on November 23, 2016 after nearly two months of significant drought conditions. Many residents of Gatlinburg and surrounding areas witnessed cues from the fire, including smoke and ash starting from November 23 to November 28, 2016 when the fire quickly spread into residential areas due to high winds, with sustained wind speeds near hurricane force [11], [12].

After-action reports outlining the timeline of events specify that around noon on November 28, first responders began disseminating voluntary evacuation notices to residents in Mynatt Park, a park and subdivision within the City of Gatlinburg and in the Turkey Nest and Savage Garden communities. Mynatt Park was the closest residential area to the Twin Creeks park boundary, where the fire had progressed by 11:30 am, and was initially believed to be the only community at risk of being threatened by the fire $[11,12]$. At this time (around 12:00 pm) dissemination of voluntary evacuation orders was mainly achieved via door-todoor notifications; however, reports document that many residents decided to stay in place [11]. Four hours later, a press conference was held in Gatlinburg to further communicate the voluntary evacuation of the Mynatt Park area and the shelter that was established at the Gatlinburg Community Center (at $\approx 1: 30 \mathrm{pm}$ earlier that day). Around the same time, the City of Gatlinburg saw intermittent power outages until the Gatlinburg City Headquarters lost power, landlines, and internet at 5:45 pm. Existing cell towers in the area also began going down, further disabling routine notification systems. At 5:00 pm, Gatlinburg officials held another press conference at which the fire chief stated: "As of this time, there is no fire in the city limits of Gatlinburg." [11].

Conditions changed rapidly between $5 \mathrm{pm}$ and $6 \mathrm{pm}$ due to strong winds from the south. At 6:08 pm, fire officials noted the fire had physically crossed the National Park's boundary and was heading towards the Park Vista Hotel. By 6:30 pm, several fires had started in the City of Gatlinburg, possibly due to embers spreading ahead of the fire front [11]. Forced into a "reactive response", fire officials declared an immediate mandatory evacuation of the Mynatt Park neighborhood at 6:11 pm and 16 min later made a similar declaration for neighborhoods along East Foothills Road, Turkey Nest Road, Davenport Road, and Savage Garden areas [11]. The public information officer for Gatlinburg issued press releases for these evacuations at 6:37 pm, adding Savage Garden in a release issued 10 minutes later.

Around 7 pm on November 28 fire was observed at the Spur (a five-mile road that connects the cities of Gatlinburg and Pigeon Forge through the GSMNP) and GSMNP officials limited the southbound entrance of the Spur near the Pigeon Forge City limits to emergency vehicle traffic only [11]. By this time, police and fire crew evacuation efforts included door-to-door and loudspeaker evacuation notifications and verification that residents had evacuated their homes in the most threatened areas including Ski Mountain, which was added as a mandatory evacuation area just before 8:00 pm. First responders implemented these efforts before an official mandatory evacuation notice was sent based on direct observations of the fire's rapid progression as multiple fire fronts approached the City of Gatlinburg and surrounding communities. Extreme fire conditions in this area prevented evacuations from being fully 
executed, and efforts were initially slowed by residents who required additional persuasion before deciding to evacuate. Sevier County deputies were ordered to evacuate Ski Mountain around 8:15 pm as the severity of the fire exceeded their ability to protect themselves, but they continued to evacuate residents for another 10 to 20 minutes. At 7:52 pm, all northbound traffic from Gatlinburg to Pigeon Forge was directed away from the Spur, and emergency officials began an on-going effort to clear the road of trees and debris to allow for evacuation and emergency vehicle traffic.

A mandatory evacuation notice was sent via e-mail to all businesses in the City of Gatlinburg at $8: 11 \mathrm{pm}$ using a database maintained by the Chamber of Commerce. Widespread power losses started across the area around 8:14 pm, complicating efforts to alert residents via thirdparty, reverse 9-1-1 systems. To combat these issues, police, fire, and mass transit personnel were sent door-to-door to evacuate residents and visitors. During this process, officials were met with downed trees and power lines, intense fire, and the loss of many communication services. Approximately 15 min later (around 8:30 pm), a mandatory evacuation of the entire City of Gatlinburg and surrounding areas was ordered, and service was lost from two cell towers covering the Gatlinburg area [11]. Two additional evacuation notices were given in the downtown Gatlinburg area using the city's manual flood warning sirens system [11].

Due to miscommunication across state and location organizations, the Integrated Public Alert and Warning System (IPAWS) was not used by the Tennessee Emergency Management Agency (TEMA) to disseminate an evacuation notice. This system would have distributed evacuation notices to both mobile devices and the Emergency Alert System (EAS), although communication system failures at the time would have limited or entirely prevented message delivery even if the message had been sent [11], [12]. Instead, the National Weather Service (NWS) disseminated two evacuation messages via EAS, noting the locations where mandatory evacuation orders had been issued. Instructions to: "evacuate immediately and [follow] any instructions from emergency officials", among other information, was disseminated via this system by the NWS, while individuals who were not in these areas and had not been instructed to evacuate were asked to "please stay off the roads" [11]. However, these messages were not sent until 9 pm for the City of Gatlinburg and surrounding areas and 9:47 pm for areas within the City of Pigeon Forge. The NWS was also unable to utilize a Wireless Emergency Alert (WEA) during the evacuation because it was a non-weather emergency [11]. Around 10:30 pm, the TEMA Director sent out an IPAWS message asking everyone to stay off mobile phones [11].

By 10:00 pm, 14000 residents and guests in the Gatlinburg area had been evacuated. By the early morning hours of November 29, 17000 acres were burned, around 2500 structures had been affected, and 14 people had died either directly from the fire or as a consequence of attempting to flee the fire. By 2:00 am, weather conditions improved until there was minimal fire spread, though firefighting efforts continued until December 5. The evacuation notice for Gatlinburg was lifted on December 9 at 7:00 am [11]. 


\section{Survey Methods}

\subsection{Sampling Strategy}

The authors, via a small business survey research firm (Fors Marsh Group located in Virginia, USA), conducted an online and telephone survey of households in fire affected and evacuated areas in and around Gatlinburg from October 29, 2018 to May 22, 2019. The sample was developed by identifying the Census blocks that were located within or touching the fire perimeter (burned areas, including ember-driven spot fires) and/or the neighborhoods noted in public evacuation notices. Then, the contractor purchased a mailing list of all available addresses within the Census blocks; this included 3997 addresses, for which phone numbers for 1996 of those addresses were also available. ${ }^{2}$ See Figure 1 in Section 2.2 for a map depicting the Census blocks used for the sample and participant counts within each block.

Members of the sampling frame (3997 addresses) were sent an initial letter inviting them to visit the survey website to complete the online survey. Each potential respondent was provided with a unique survey code that allowed them to access the survey. Later in the survey fielding period, those in the sampling frame who had not yet completed the survey were mailed two reminder postcards asking them to visit the survey website to complete the survey. Additionally, following the initial invitation letter sample members for whom a phone number was available (i.e., 1996 of those addresses) also received a phone call inviting them to participate in the survey via telephone. For sample members who did not answer the phone, survey administrators left a phone message containing the survey web address and other survey information. (Reminder postcards also contained a phone number that participants could call to complete the survey by telephone). This recruitment strategy began on October 29, 2018 and ended in April 2019.

Of those contacted in the initial Census mailing, 178 completed the survey online, and 32 completed the survey by phone. This resulted in a combined (online and phone) initial response rate of $9.2 \%\left(210\right.$ out of $\left.2,288^{3}\right)$. In an effort to obtain additional responses and reach households that were potentially no longer at the same address they had occupied in November 2016, the research team supplemented the mail and phone outreach with a targeted online advertising campaign focused on the Gatlinburg area. In this second recruitment strategy, advertisements for the survey were placed on local news websites, followed up by a press release to the same news outlets. In addition, online advertisements for the survey were placed on Facebook reaching users within a 15-mile radius of Gatlinburg. This second recruitment strategy began April 1, 2019 and ended on May 22, 2019, when the online survey was deactivated.

\footnotetext{
${ }^{2} 1217$ of the 3997 addresses identified were marked as unable to receive mail. This proportion of undeliverable mail is higher than the expected $8 \%$ to $13 \%$ undeliverable mail; however, it is explainable in this location as vacation homes and other rental properties are more common. With that said, researchers made one attempt to reach the 1217 "undeliverable" addresses with the goal of maximizing survey responses from those who might have experienced the fire.

${ }^{3}$ Of the 3997 survey invitation letters initially sent, 1709 were returned as undeliverable, making the final mailing sample 2288.
} 
This second round of outreach yielded an additional 178 completed survey responses, making the total number of completed survey responses 388 . See Table 1 below for a summary of the outreach methods and associated responses.

Table 1. Survey Contact Methods and Response.

\begin{tabular}{|c|l|}
\hline & $\boldsymbol{N}$ \\
\hline Total responses & 388 \\
\hline Online: & 356 \\
\hline Original Mail & 178 \\
\hline Ads: & 178 \\
\hline Facebook & 153 \\
\hline Mountain Press & 4 \\
\hline WATE.com & 1 \\
\hline WVLT.tv & 0 \\
\hline Unknown market $^{\mathbf{4}}$ & 20 \\
\hline Phone $^{\mathbf{5}}$ & 32 \\
\hline
\end{tabular}

\subsection{Final Study Sample}

After the 388 completed survey responses were collected, an additional screening exercise was conducted to ensure that participants selected for analysis were directly involved in the 2016 Chimney Tops 2 fire and resulting evacuation decisions. The screening items used in this exercise were home location (recorded by the contractor as their Census block to protect participant privacy) and a question of where the participant was at the time of the fire. Based on this information, 65 of the 388 participants were removed from the final sample. Specifically, 22 individuals whose home addresses were not provided or could not be confirmed were removed from the sample. Additionally, 42 online respondents whose home addresses were not within the original mailing area and reported that they were at home at the time of the fire (e.g., and not at work in downtown Gatlinburg) were also removed from the sample. Finally, one individual who stated to be out of town during the fire event was removed. This screening exercise yielded a final sample of 323 participants.

See Figure 1 for a map of the fire-affected sample area; participants outside of the sample boundary (in purple) were generally removed from the final sample based on the guidelines described above. (For a description of sample socioeconomic characteristics and comparison to country Census data, see Section 3.1).

\footnotetext{
${ }^{4} 20$ respondents accessed the survey through advertisements, but the research team was unable to determine which specific market they came from.

${ }^{5}$ Only original frame cases supplied completed surveys by phone.
} 


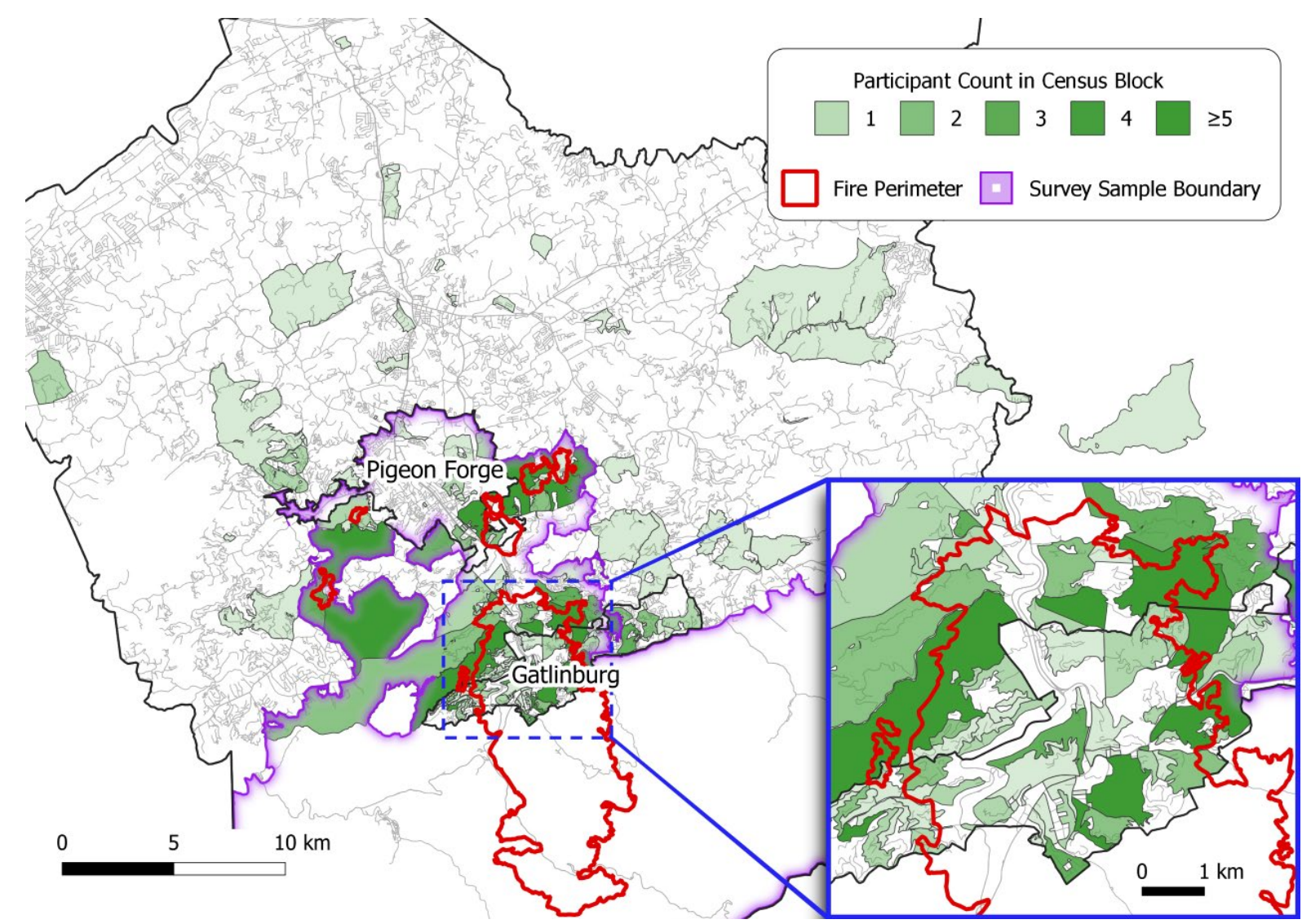

Figure 1. Map of Responding Participants and Sample Area.

\subsection{Survey Instrument}

The authors developed a household survey to collect data on a variety of factors identified in wildfire evacuation literature to be influential on both risk perception and the decision to evacuate. The first step in survey development was to gather surveys from other wildfire evacuation studies both in the U.S. [13] and in Australia [8, 14] and an additional survey conducted by the US Army Corps of Engineers (US ACE) on evacuation behavior during the 2017 Oroville dam event [15]. Since the focus of this study was exclusively on evacuation decision-making in wildfires (and the data would also be used to validate a previously developed evacuation decision model based on the Protective Action Decision Model), no one survey was used outright. Instead, certain questions or sets of questions from all four surveys were adapted to eventually develop a comprehensive survey for this study of the Chimney Tops 2 fire.

Items in the survey assessed several pre-event and sociodemographic variables, including awareness of the risk (Before the Chimney Tops 2 fire, did you know that wildfires could be a problem in your community?), binary items to assess preparedness actions (Had you or others (e.g., family, friends, businesses) taken any measures to protect your residence from wildfires? and (Did you have a household emergency plan for wildfires in place before the 
Chimney Tops 2 fire?), previous experience in wildfire evacuation (How many times in the past 10 years (decade) did you evacuate your home/neighborhood/workplace (or other location) because of a wildfire?), and socio-demographics, including gender, race/ethnicity, age, education, income, family size and number of pets/livestock, and length and type of residence (i.e., rent/own).

The survey also included questions related to the warnings and cues associated with the fire event. More specifically, respondents were first asked: "Did you receive any warnings about a wildfire occurring that could threaten your town/city or residential area?" If they answered yes, participants were directed to a series of questions asking about the location, date, and time of day when they received a first warning and/or additional warnings, and the respondents' characterization of that warning(s), including its content, dissemination method (i.e., channel), and source. In addition, all participants were asked who they considered to be "the most credible source of information about wildfire events."

After answering questions on warnings, respondents were directed to a section of the survey (or routed via skip logic, if they received no warnings) that asked about fire cues. More specifically, respondents were asked whether they received: "any information about the Chimney Tops 2 fire from the fire itself, e.g., seeing, hearing, feeling, or smelling the fire such as flames, smoke, embers, etc." If they answered yes, participants were directed to a series of questions on the types of fire cues received, and the location, date, and time of day when they received the cues.

Additionally, data were collected on respondents' perceptions of threat and risk at various times in their decision-making process using scales adapted from the Oroville dam event survey [15]. Specifically, they were asked their perception of risk when obtaining their first warning (if any), fire cues (if any), and at the time of their evacuation decision by asking using the following 4 items: How much would you say you agreed with each of the following statements on a scale of 1 to 5 where 1 represents "not likely" and 5 represents "extremely likely: 1) I might become injured, 2) Other people/pets/livestock might become injured, 3) I might die, 4) Other people/pets/livestock might die.

Lastly, items asked if participants decided to stay in place or evacuate in the 2016 wildfire event (a binary item) and the day and time of this decision, the final (actual) action taken, the main reasons for ultimately taking that action (as select-all-that-apply items), and any preevacuation/delay actions taken. For a full list of survey items, see Appendix A.

This project received expedited review by the NIST Institutional Review Board (IRB), was approved on August 6, 2018 and then renewed again the following year until June 3, 2020. All participants were requested to provide their informed consent before participating in the survey. The informed consent statement outlined the purpose of the project, the proposed use of the data, and protections provided by NIST researchers for all data collected. 


\subsection{Data Recoding and Analysis}

Completed survey responses were entered into IBM SPSS version 26. Prior to running statistical analyses, a targeted recoding effort was conducted for those participants that chose to provide end of survey comments $(\mathrm{N}=143)$. The comment's content was not directed or restricted in any way, and of the 323 responses included in our final sample 143 individuals (44.3\%) shared an optional end-of-survey comment. This effort was made to account for a suspected misunderstanding of survey instructions, where some participants responded that they received no warnings or fire cues in response to survey prompts, yet clearly described these events in qualitative descriptions of their experiences at the end of the survey.

The qualitative analysis software ATLAS.ti version 8.4 was used for the targeted recoding based on all 143 end-of-survey comments offered by participants. During four sets of iterative codebook development and coding sessions, three team members discussed capturing content related to warnings and cues in line with existing survey variables. When the team felt they had captured the concepts and their appropriate context in a codebook, two team members completed coding independently and conducted an intercoder check on $20 \%$ of the comments selected at random. Intercoder analyses yielded a percent agreement of 92.3 $\%$, and a Kappa of 0.954 . In all, 34 participants had data points added to variables relating to the presence, source, and/or type of warning or cue they experienced.

Following the above recoding effort, descriptive statistics reported in Section 3 (e.g., frequencies and means of responses) for the final sample of 323 participants were calculated in SPSS.

A thematic analysis method [16] was also used to summarize and describe the central concepts shared in the end-of-survey comments reported in Section 4. To begin, respondent comments were read repeatedly by two team members, and a list of initial codes (i.e., all topics raised by participants) was developed. Following thorough discussion and review of these codes, the following four main themes were identified: information and communication on the day the fire spread into Sevier County (November 28), the evacuation experience, fire aftermath and recovery, and general comments. Over the course of several iterative sessions, these themes, their associated codes, and the codebook were further refined between the two team members until the final versions of each were developed, namely, when themes and codes were coherent, clearly distinguishable, and captured the great majority of concepts raised by participants. Following the final refinement of codes and a corresponding codebook, one team member coded all 143 comments. Please see Braun \& Clarke, 2006 [16] for more details on the thematic analysis methodology. 


\section{Descriptive Survey Results}

The following sections will provide descriptive and graphical summaries of pertinent survey data. These results will be grouped into: 1) the sociodemographic characteristics of the survey sample, 2) pre-event fire awareness and preparation levels, 3 ) the warnings participants received prior to evacuating or deciding to stay, 4) the fire cues participants received prior to evacuating or deciding to stay, 5) risk perceptions and the evacuation/stay decision process, and 6) the main reasons why participants ultimately evacuated or stayed, including sources of delay prior to departure.

\subsection{Sociodemographic Characteristics of the Sample}

At the conclusion of the survey, participants were asked to voluntarily share personal information such as their age, gender, income, and race. Where available, these responses are compared to Census data for Sevier County, TN (population 96 000) (Census, 2018). In total, our survey sample is closely representative of Sevier County in terms of gender and race (majority white). However, the sample is possibly older, better educated and has higher household income and rates of homeownership than the County on average.

To begin, our sample was fairly well-balanced between men and women, where 174 survey respondents responded 'female' $(54.7 \%)$ and 144 responded 'male' $(45.3 \%)^{6}$.

Our sample comprised of mostly older individuals, and the median age category was 5564 years old. More specifically, $0.6 \%$ of participants were $18-24$ years old, 5.9 \% were 25-34 years old, $9.0 \%$ were $35-44$ years old, $21.1 \%$ were $45-54$ years old, $32.0 \%$ were $55-64$ years old, $23.9 \%$ were $65-74$ years old, and $7.5 \%$ were 75 years or older. Compared to US Census data (2018) for Sevier County, TN, our sample is slightly older than the median age for the county (42.7 years). However, it should be noted that participation in our survey was restricted to adults, aged 18 or older.

Participants were also asked if they had a medical condition at the time of the fire; the majority $(63.3 \%)$ reported that they did not, while $36.7 \%$ reported that they did.

Of those who self-reported household income $(\mathrm{N}=261)$, the median income category was $\$ 50000$ to $\$ 74999$, and fairly evenly distributed among income groups between $\$ 15000$ and $\$ 149$ 999. (See Figure 2 for further details). When comparing these results to Census data, the median income category (\$50 000 to \$74 999) is higher than the 2018 median household income of $\$ 45943$ for Sevier County. Note however that many participants $(N=62)$ chose not to respond to this question, and so there is the possibility that this result is not wholly representative of the study sample.

\footnotetext{
${ }^{6}$ Not all question responses total to 323 due to missing data. Valid percentages are reported throughout report. Response n's will be reported for cases where a notable number of participants ( $>15$, or $5 \%$ of sample) refused to respond or skipped the item via skip-logic.
} 
Household Income of Respondents

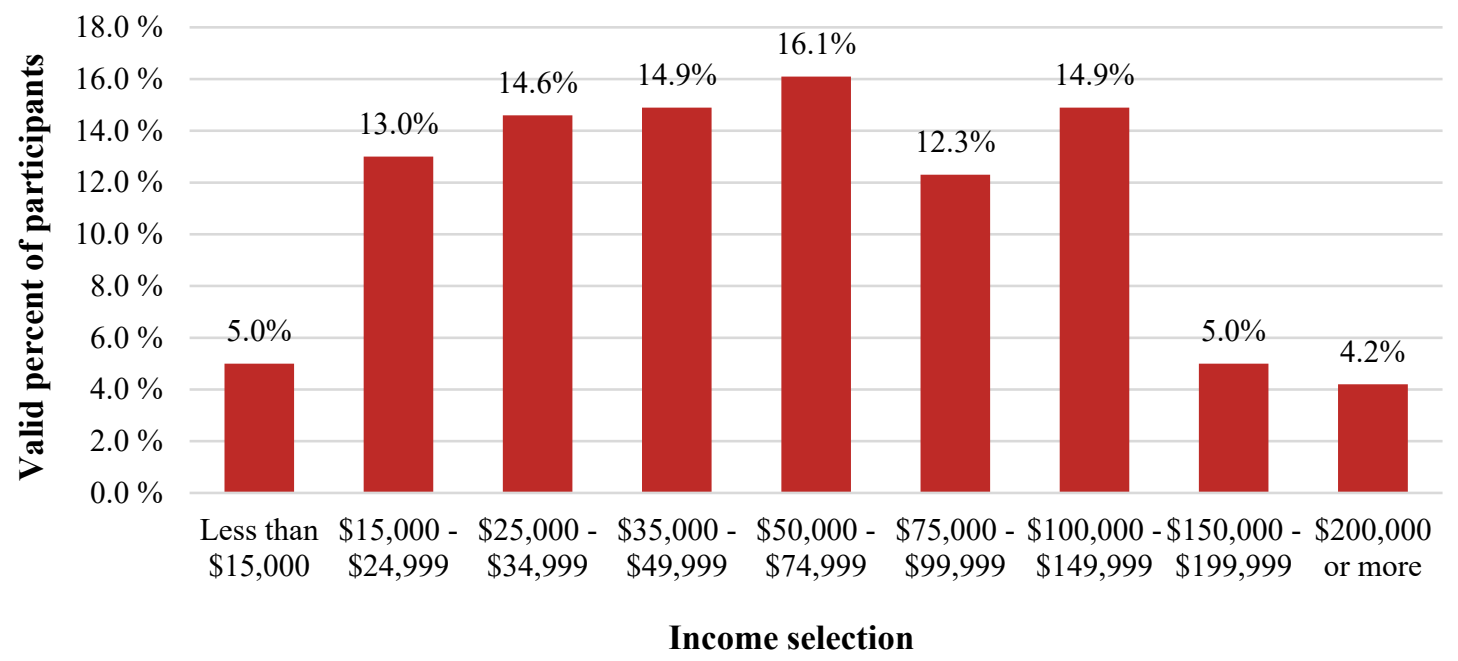

Figure 2. Income category selection among responding participants $(\mathrm{N}=261)$.

Of the participants who shared their education level $(\mathrm{N}=313), 1.9 \%$ had less than a high school diploma, $16.6 \%$ had a high school diploma or equivalent degree, $31.0 \%$ had completed some college but had not earned a degree, $10.9 \%$ had an Associate's degree, $20.8 \%$ had a Bachelor's degree, and $18.8 \%$ had a graduate degree. Compared to Census data, this sample is more highly educated than the population of Sevier County, with $98.1 \%$ of the sample having a high school degree or higher compared to $83.9 \%$ of Sevier County residents. Additionally, $20.8 \%$ of survey participants had a Bachelor's degree compared to $11.1 \%$ of Sevier County residents, and $18.8 \%$ of responding survey participants had a graduate or professional degree compared to $6.0 \%$ of County residents.

In terms of racial identity, the large majority of survey respondents were White (94.4\%). Additionally, $2.2 \%$ indicated that they were Hispanic or Latino, $1.9 \%$ were American Indian or Alaskan Native, and $2.8 \%$ (9) elected not to answer. No participants identified themselves as Black or African American, Asian, or Native Hawaiian or Pacific Islander. This sample is quite similar to Census data, where $94.8 \%$ of Sevier County was recorded as White in 2018. As for unrepresented races in our sample, the Census reported that $0.8 \%$ of the population was Black or African American in 2018, $0.9 \%$ was Asian, and $0.0 \%$ was Native Hawaiian or Pacific Islander.

Next, the majority of participants in our sample who shared their employment status at the time of the fire were employed (including self-employment): $41.8 \%$ worked full-time ( 40 or more hours per week), and $19.5 \%$ worked part-time (fewer than 40 hours per week). A sizable proportion of our sample was also retired $(31.1 \%)$, and $5.3 \%$ reported that they were disabled. In addition, $1.3 \%$ were not employed, and $0.9 \%$ identified themselves as a stay-athome parent. Compared to Census data, which reported an employment rate of $58.8 \%$ in 2018 , the employment rate for our sample (61.3\%) is slightly higher than that of Sevier County. 
In terms of homeownership and residence length at the time of the fire, $77.0 \%$ of respondents in our sample owned their homes, and $23.0 \%$ were renting (See Figure 3,). The homeownership rate $(77.0 \%)$ for this sample is high compared to the Census reported rate of $68.1 \%$ for Sevier County in 2018.

Most participants had also lived in the community for an extended time: at the time of the fire, $10.9 \%$ had lived in their homes for less than 1 year, $10.0 \%$ for $1-2$ years, $13.7 \%$ for 34 years, $17.1 \%$ for $5-10$ years, and $48.3 \%$ for 10 or more years. (See Figure 4 ).
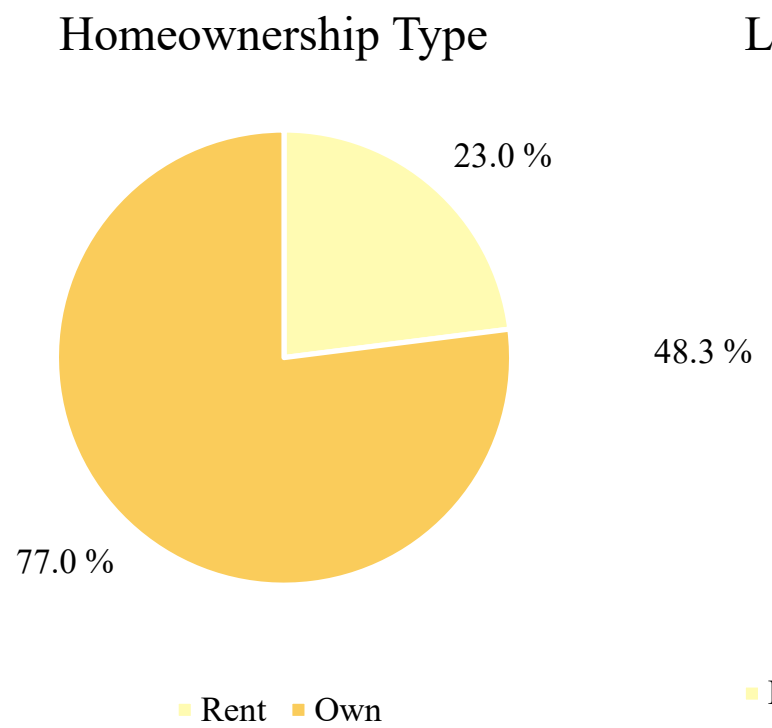

Length of Area Residence

Rent $₫$ Own

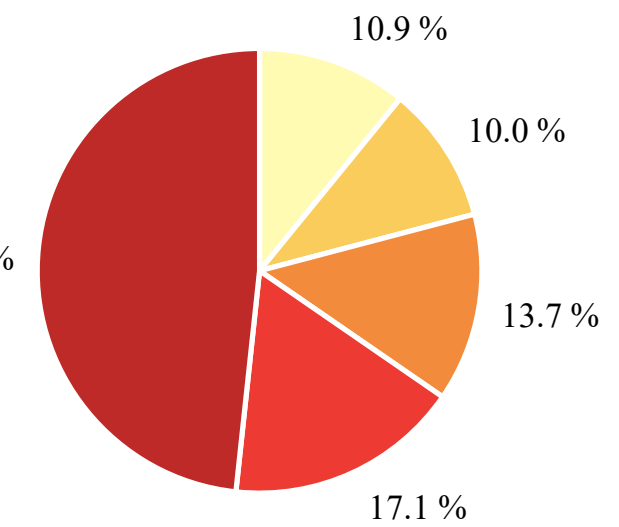

$$
\begin{aligned}
& \text { Less than } 1 \text { year } \quad 1-2 \text { years } \\
& =3-4 \text { years } \quad-5-10 \text { years } \\
& \text { - } 10+\text { years }
\end{aligned}
$$

Figures 3 and 4. Survey participant homeownership rate (left; $N=309$ ) and length of area residence (right; $\mathrm{N}=321$ ) among responding participants.

Our survey also asked participants how many children, adults, and elderly people, including themselves, were in their household at the time of the fire. First, $20.2 \%$ of the sample reported having children at home: $10.3 \%$ of the sample had one child, $7.5 \%$ had two children, $1.2 \%$ had three children, and $1.2 \%$ had four or more children. Additionally, $38.0 \%$ had at least person 65 years of age or older in their home at the time of the fire (note that the respondents could include themselves in these counts).

Participants were also asked how many pets or livestock they had at the time of the fire. A majority of participants $(67.6 \%)$ had at least one pet, while only a small number of participants reported having livestock (2.5\%). Of those who owned livestock, half (4) had 10 or fewer animals, while the other half had more than 10 (up to 75) animals. 


\subsection{Pre-Event Factors: Fire Awareness and Preparation}

Before being asked about their experiences in the Chimney Tops 2 fire, participants were first asked questions related to their pre-event awareness of wildfire risks and fire preparation. These variables included awareness that wildfires could pose a threat to their community, preparation actions taken prior to the fire event, established household emergency plans, and prior evacuation experience. Overall, participants in our sample were usually unaware of wildfire risks prior to the Chimney Tops 2 event, and most did not have evacuation plans or personal experience with evacuations.

Prior awareness of fire risks was measured with two items. First, participants were asked if they knew that wildfires could be a problem in their community prior to the Chimney Tops 2 event (yes/no). Of those who responded to this item $(\mathrm{N}=304), 50.7 \%$ of respondents indicated that they were not previously aware that there were fire risks in their area. The second item asked participants how likely they thought that a wildfire could threaten their property, using a $1-5$ scale where $1=$ "No possibility at all" and $5=$ a "Very good possibility." In response to this question, only $10.0 \%$ of participants believed there was a "very good possibility" of a wildfire threatening their property prior to the Chimney Tops 2 fire, while $27.5 \%$ felt that there was "No possibility at all". The mean of responses to this item was below the midpoint, at $2.33(\mathrm{SD}=1.21)$. See Figure 5.

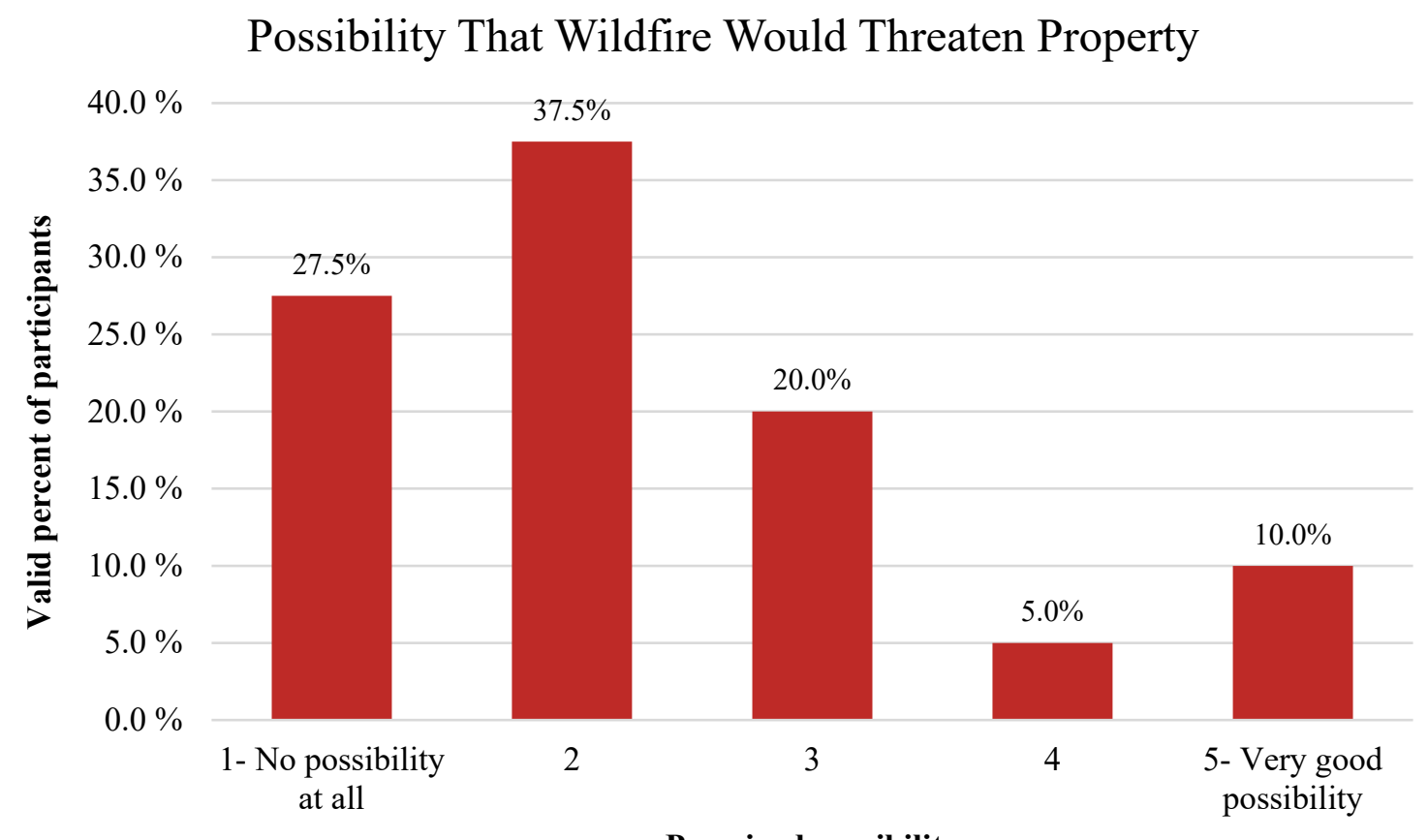

Perceived possibility

Figure 5. Perception that a wildfire could threaten property prior to Chimney Tops 2 among responding participants $(\mathrm{N}=320)$. 
Participants were then asked to describe prior preparation actions taken to protect their residence from wildfires by selecting any of four options: removing fuels, moving fuels away from the home (e.g., woodpiles, mulch, etc.), installing sprinklers, and modifying structures. The majority of participants $(55.7 \%)$ had taken none of these preparation actions. Of the $44.3 \%$ of participants that selected at least one option, removing fuels was the most common (30.0\% of the sample). Installing sprinkler systems and modifying structures were much less common. See Figure 6.

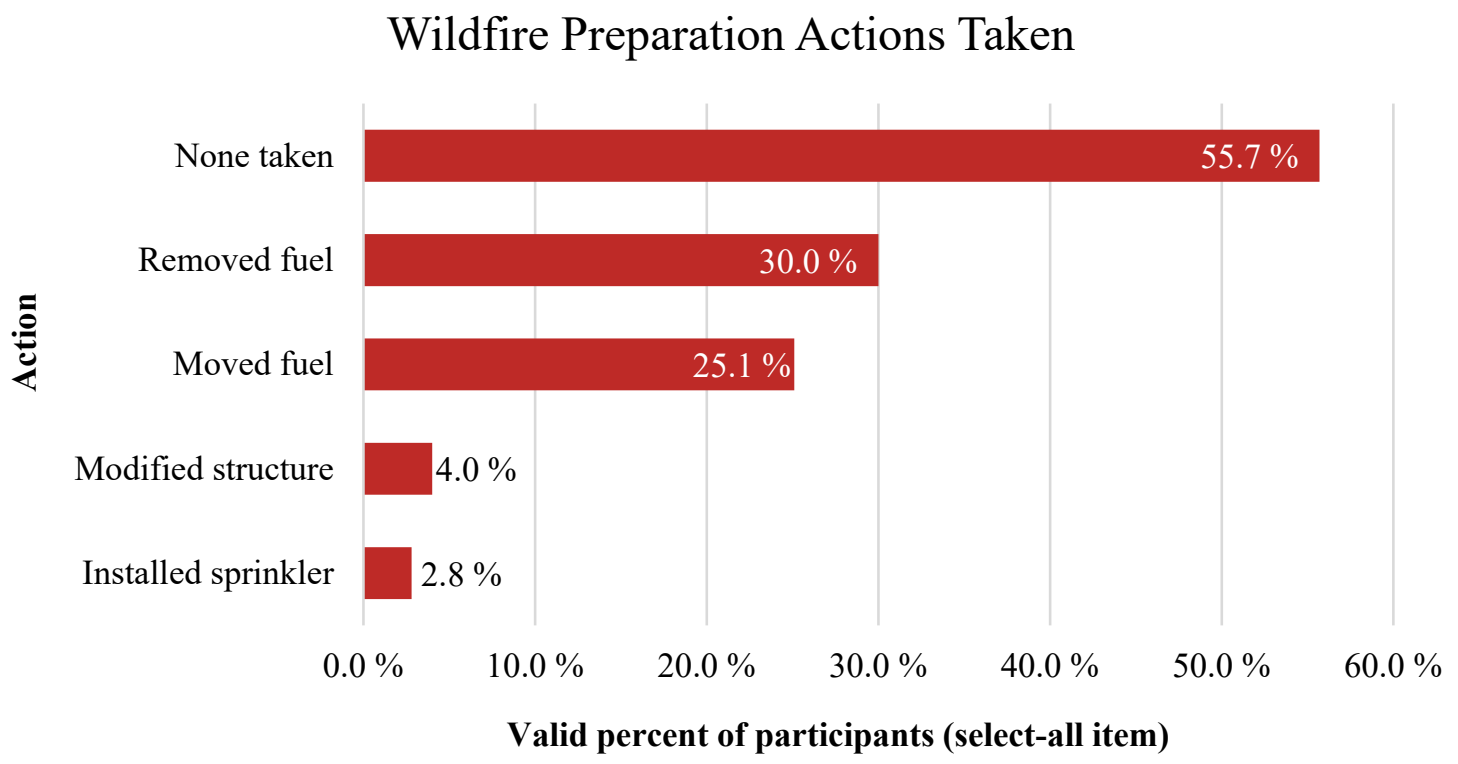

Figure 6. Protective actions taken prior to the fire event among responding participants $(\mathrm{N}=$ $323)$.

Next, only $18.3 \%$ of participants had a household emergency plan prior to the fire. Of those who had an emergency plan $(\mathrm{N}=59)$, the ultimate goal was usually to evacuate before the fire spread to their home ( $16.7 \%$ of sample; 54 individuals), compared to a much smaller number whose plan was to stay in place (only 2 individuals).

Lastly, participants were asked about any prior experience with wildfire evacuation. The great majority, $95.0 \%$, of the sample had not ever evacuated (defined as leaving and travelling to a different/safer place) due to a wildfire prior to the Chimney Tops 2 fire. Of the $5.0 \%$ who had prior evacuation experience, 14 participants had evacuated one time, and two had evacuated 2-3 times because of a wildfire. 


\subsection{Warnings Received}

Participants were next asked questions concerning the warnings they received in the time period between November 23, 2016 when the Chimney Tops 2 fire was detected and November 28, 2016 when the fire spread into Sevier County (i.e., before they decided to evacuate or began evacuating). Participants were first asked: "In this time period, did you receive any warnings about a wildfire occurring that could threaten your town/city or residential area?". Participants who answered "yes" were then asked about the time the first warning was received, types of information included in the warning(s), warning channel(s), warning source(s), and their most trusted source of wildfire information. Overall, most individuals in our sample reported receiving no warnings prior to evacuating. Those who did receive a warning most commonly got them from social sources (e.g., family, friends, or neighbors) rather than official sources, and they typically received their first warning on the day (November 28) the fire spread into Sevier County.

To begin, $22.6 \%$ of the sample $(\mathrm{N}=73)$ reported receiving a warning about the Chimney Tops 2 fire before the fire spread to Sevier County on November 28. Out of the entire sample (323), 3.1\% responded that they received an official evacuation order during that time, $5.0 \%$ remembered receiving an evacuation recommendation or voluntary evacuation notice, and a larger $16.5 \%$ remembered receiving more general information about the fire (i.e., that was not an official or voluntary evacuation notice).

All participants were also asked how many total official warnings they received before they began evacuating. The large majority of participants $(83.0 \%)$ did not remember getting official warnings at any time. $17.0 \%$ of the sample indicated that they received a warning that they would classify as an official or mandatory evacuation warning before they evacuated, $11.0 \%$ remembered receiving one, $4.1 \%$ receiving two, $1.3 \%$ receiving three, and $0.6 \%$ remembered receiving four or more of these warnings. See Figure 7.

\section{Number of Official or Mandatory Evacuation Warnings}

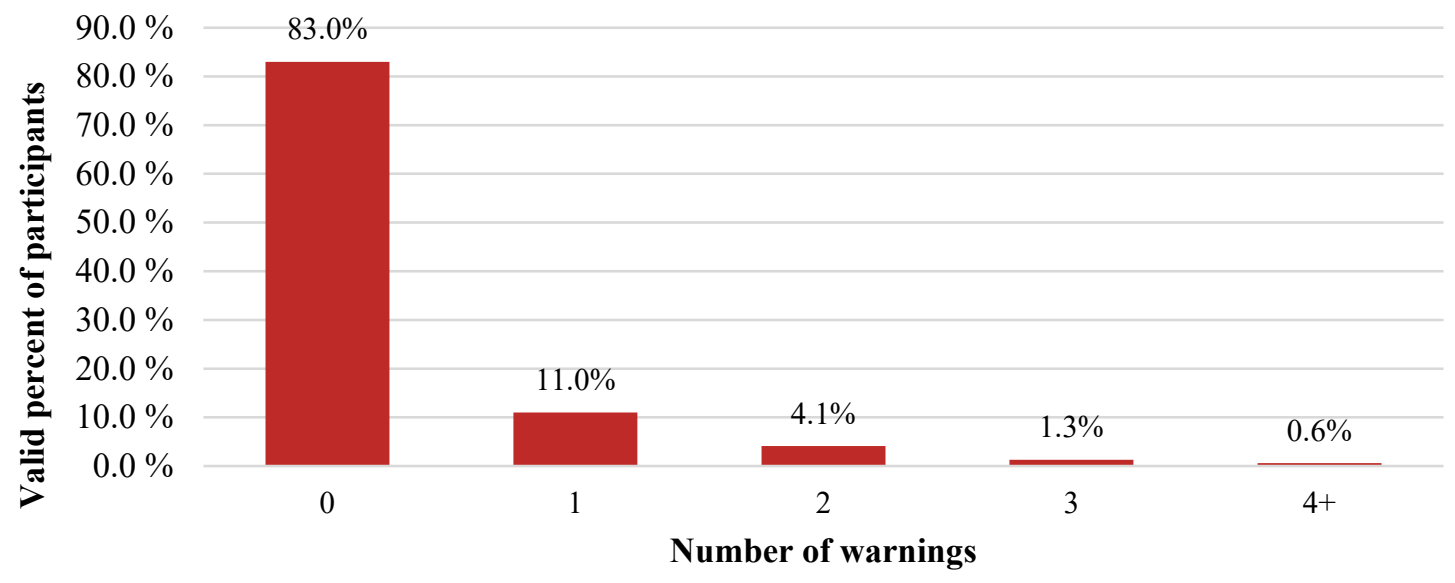

Figure 7. Number of official or mandatory evacuation warnings received prior to evacuation among responding participants $(\mathrm{N}=318)$. 
Participants who received official or unofficial warning $(\mathrm{N}=73)$ prior to the fire spreading beyond the GSMNP boundary were asked to also provide the date they remember receiving their first warning. Of those who provided dates for their first warning (64 participants), $9.4 \%$ remembered receiving a warning before the fire at Chimney Tops 2 was detected (likely due to smoke from other fires in the surrounding areas) and $7.8 \%$ received a warning on the day the fire was detected (November 23). $20.1 \%$ received this warning between the detection and spread of the fire (November 24 to November 27). The majority (62.5\%), however, received their first warning on the day the fire crossed the National Park boundary (November 28), and $1.6 \%$ received their first warning the day after the fire spread to residential areas. See Figure 8.

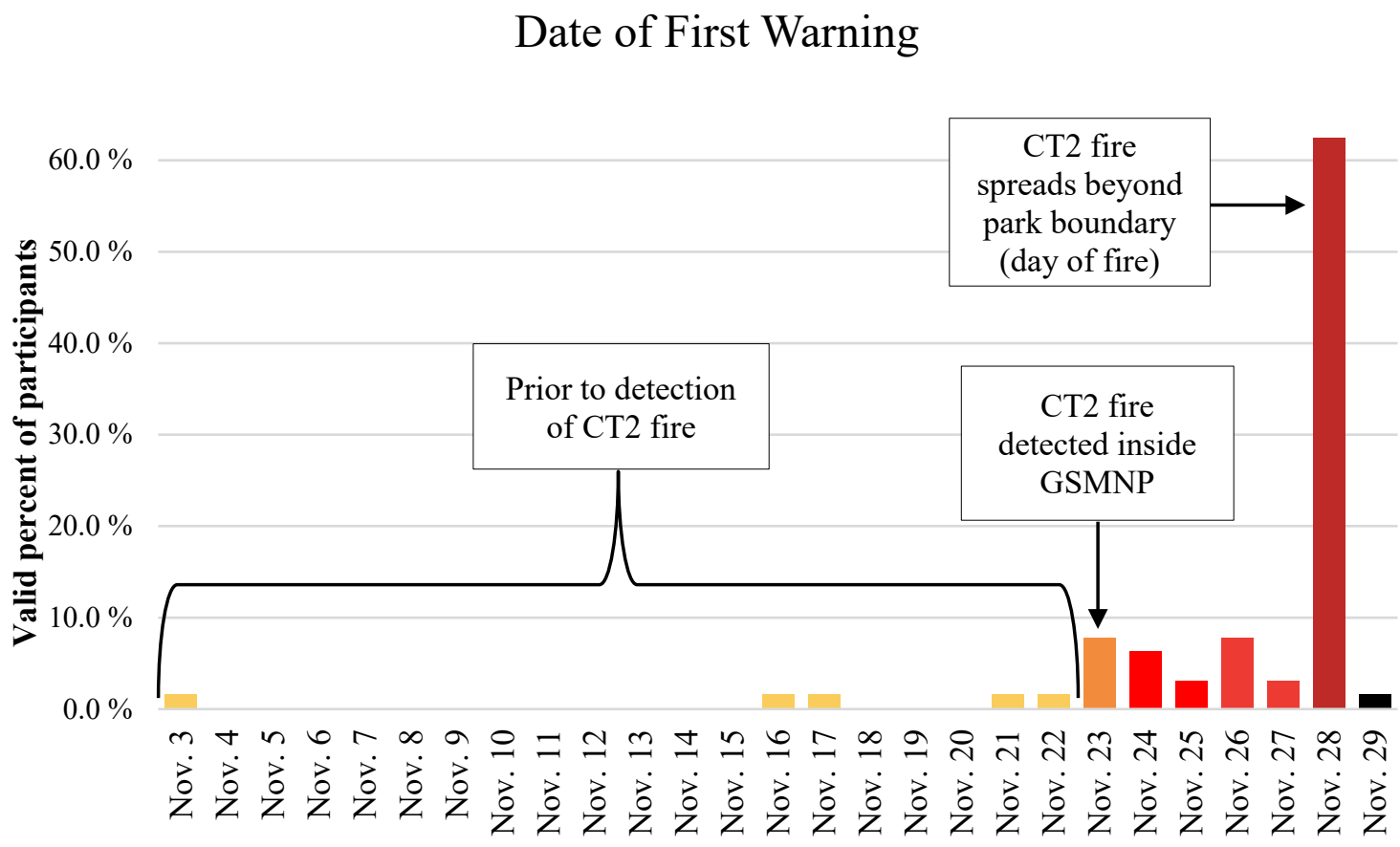

Date warning was received

Figure 8. Timeline of when participants received their first warning(s) among those who received a warning and provided a specific date $(\mathrm{N}=64)$.

Participants $(\mathrm{N}=73)$ who indicated that they received warnings were also asked to describe the information included in the warning and were able to select more than one type of information. The most common information recalled was about the wildfire's location, which was reported by $71.2 \%$ of participants who received warnings $(\mathrm{N}=52)$, followed by information about the fire's severity ( $31.5 \%$ ), and less commonly suggested protective actions $(13.7 \%)$, the status of evacuation routes from the community $(12.3 \%)$, the wildfire's expected arrival time at their location $(8.2 \%)$, and available time for evacuation $(8.2 \%)$. 
Participants $(\mathrm{N}=73)$ who received warnings additionally provided all the sources of the warnings they remembered receiving. Overall, the most common source of warnings were "unofficial" or social sources such as neighbors, friends, family, reported by $58.9 \%$ of those who received a warning. Messages from official sources such as police or fire departments or a federal agency were received by $30.1 \%$. See Figure 9 for details on individual sources.

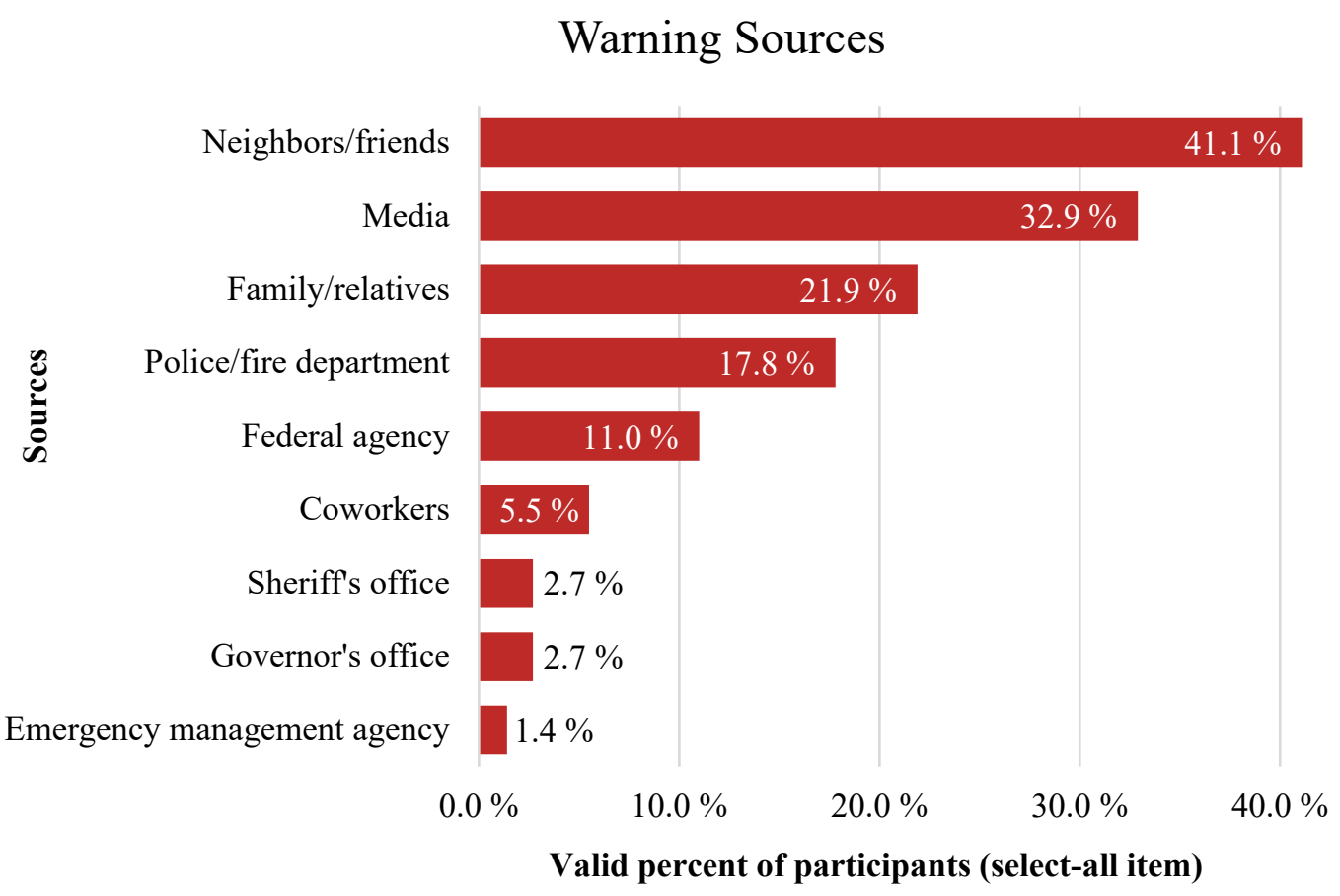

Figure 9. Sources of warning messages among those who received warnings $(N=73)$.

As with message source, participants who received warnings $(\mathrm{N}=73)$ were able to select all of the channels they remembered receiving warnings through, regardless of the source. The most common channels were via a phone call (32.9\%), in-person $(30.1 \%)$, or television broadcast (30.1\%). See Figure 10 for further details. 


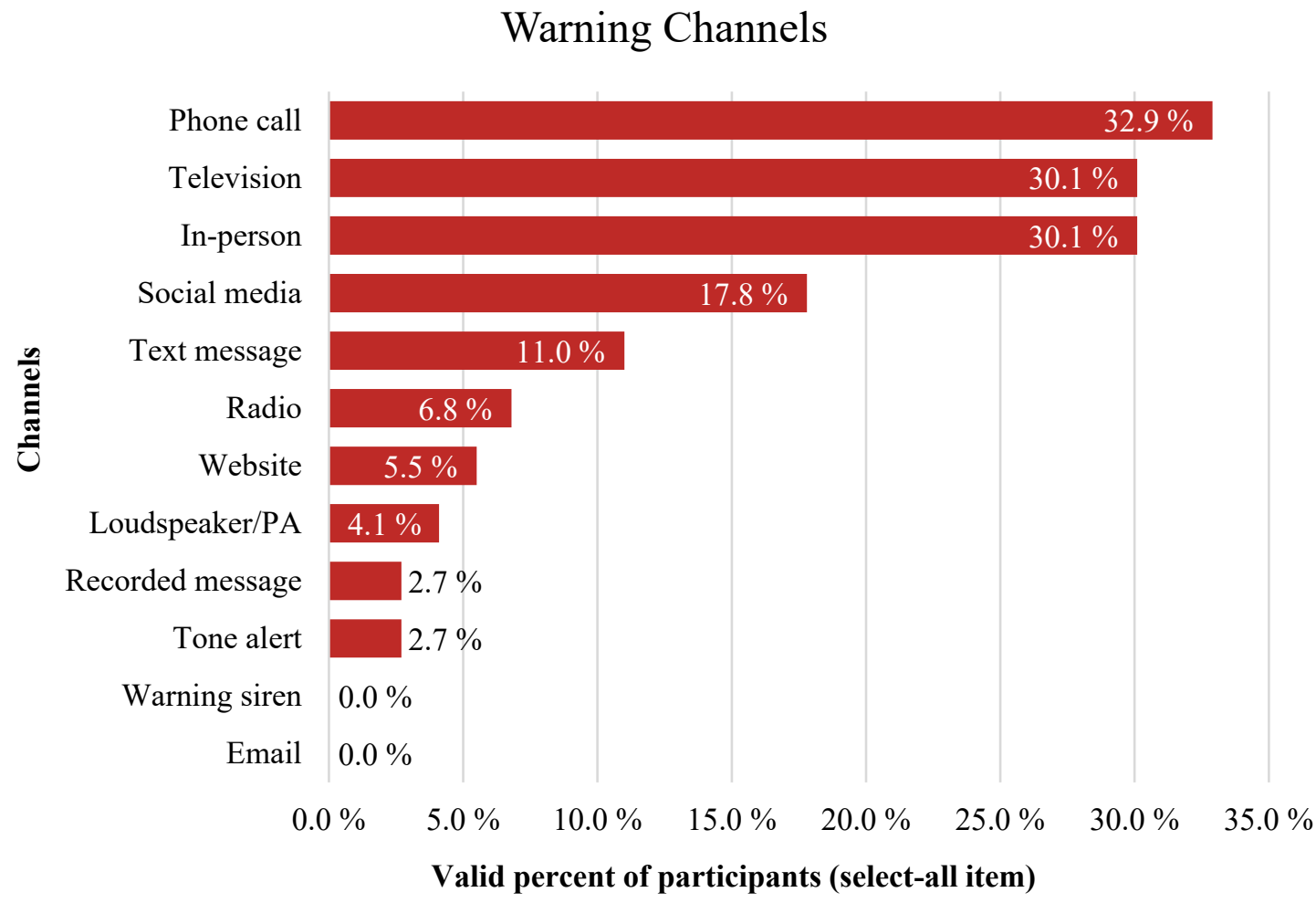

Figure 10. Channels of warnings messages among those who received warnings $(N=73)$.

Lastly, all participants were asked who they considered to be the most credible source of information about wildfire events. Police and fire departments were most common (48.4\%), followed by emergency management agencies (15.4\%). See Figure 11 for further details.

\section{Most Credible Source of Information}

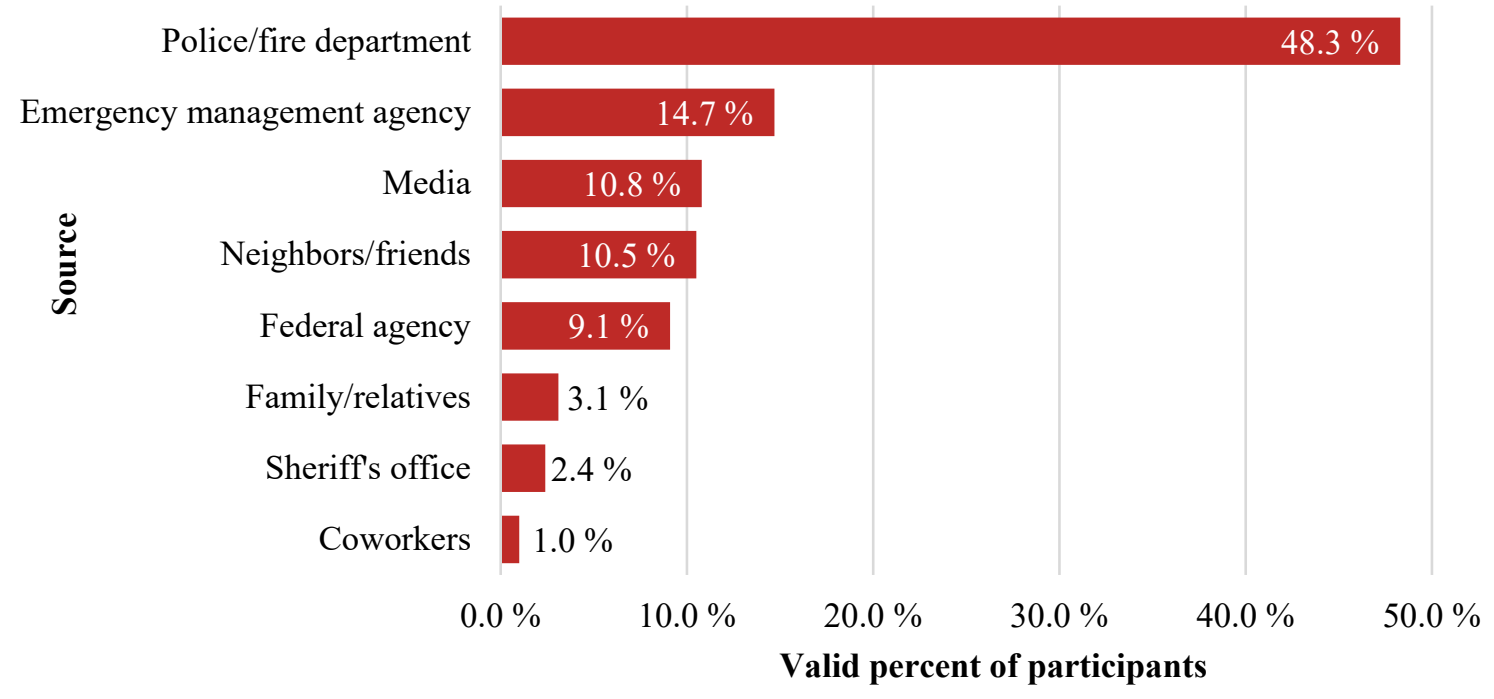

Figure 11. Sources perceived to be most credible sources of wildfire information $(\mathrm{N}=286)$ 


\subsection{Fire Cues Received}

In addition to information they received from official, social, and media sources, participants were also asked about any information they obtained from the fire itself. Fire cues observed (from select-all items) included flames, embers, smoke, winds, and heat, and participants additionally stated seeing an orange or red glow in the sky and falling ash. While some participants observed fire cues prior to the day the fire spread to residential areas (likely as smoke), the majority of participants reported observing fire cues the day the fire spread into Sevier County; November 28.

First, participants were asked to select all the types of fire cues they remembered observing before they decided to evacuate or stay in place. Nearly three-quarters of the sample (74.6\%; 241) reported that they observed cues that provided them information about the wildfire threat.

Most commonly, $92.5 \%$ of those who observed fire cues $(\mathrm{N}=223)$ reported that they saw or smelled smoke, followed by $67.6 \%$ who observed high winds, $46.5 \%$ who saw embers (defined as: "small or larger pieces of burning or glowing materials flying past your property or landing on your property"), $43.2 \%$ saw flames, and $24.1 \%$ said they actually felt the heat of the fire. Participants additionally had the option to describe any "other" cues they observed that were not already listed: notably, $5.0 \%$ of those who observed fire cues commented that they saw an orange or red glow in the sky, and $4.6 \%$ saw ash in the air or on the ground. See Figure 12.

\section{Types of Fire Cues Observed}

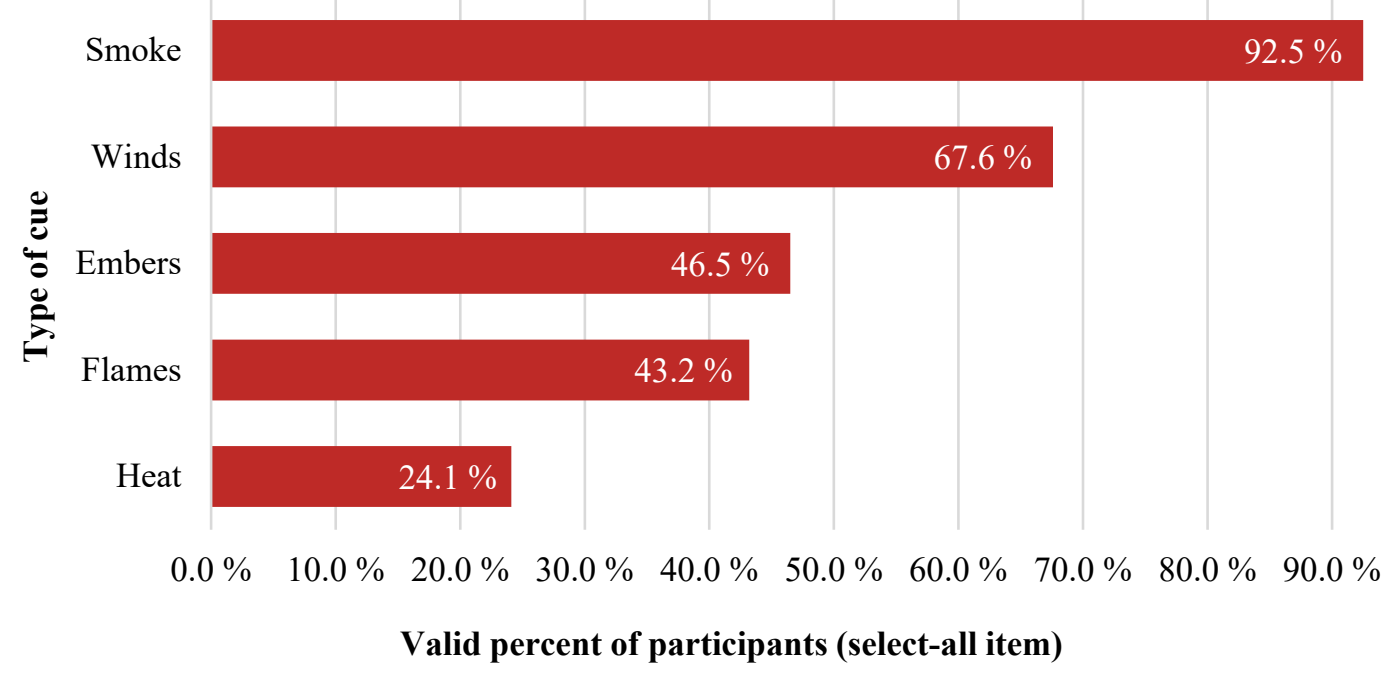

Figure 12. Types of fire cues among those who observed them $(\mathrm{N}=241)$. 
Participants who received fire cues $(\mathrm{N}=231)$ were also asked when they observed any or all of these fire cues. $68.4 \%$ of participants remembered observing them on the day the fire spread into Sevier County (November 28). Another $19.1 \%$ observed cues between when the fire was detected and spread (November 24 to November 27), 5.2 \% reported observing cues on the day the fire was discovered (November 23), and $2.6 \%$ reported that they observed fire cues after the day of the fire (November 29 to November 30). Some participants (4.8\%) reported that they observed fire cues before the fire on Chimney Tops 2 was even detected (prior to November 23, and as early as November 1 - likely as smoke from other fires). See Figure 13.

\section{Date Fire Cue(s) Observed}

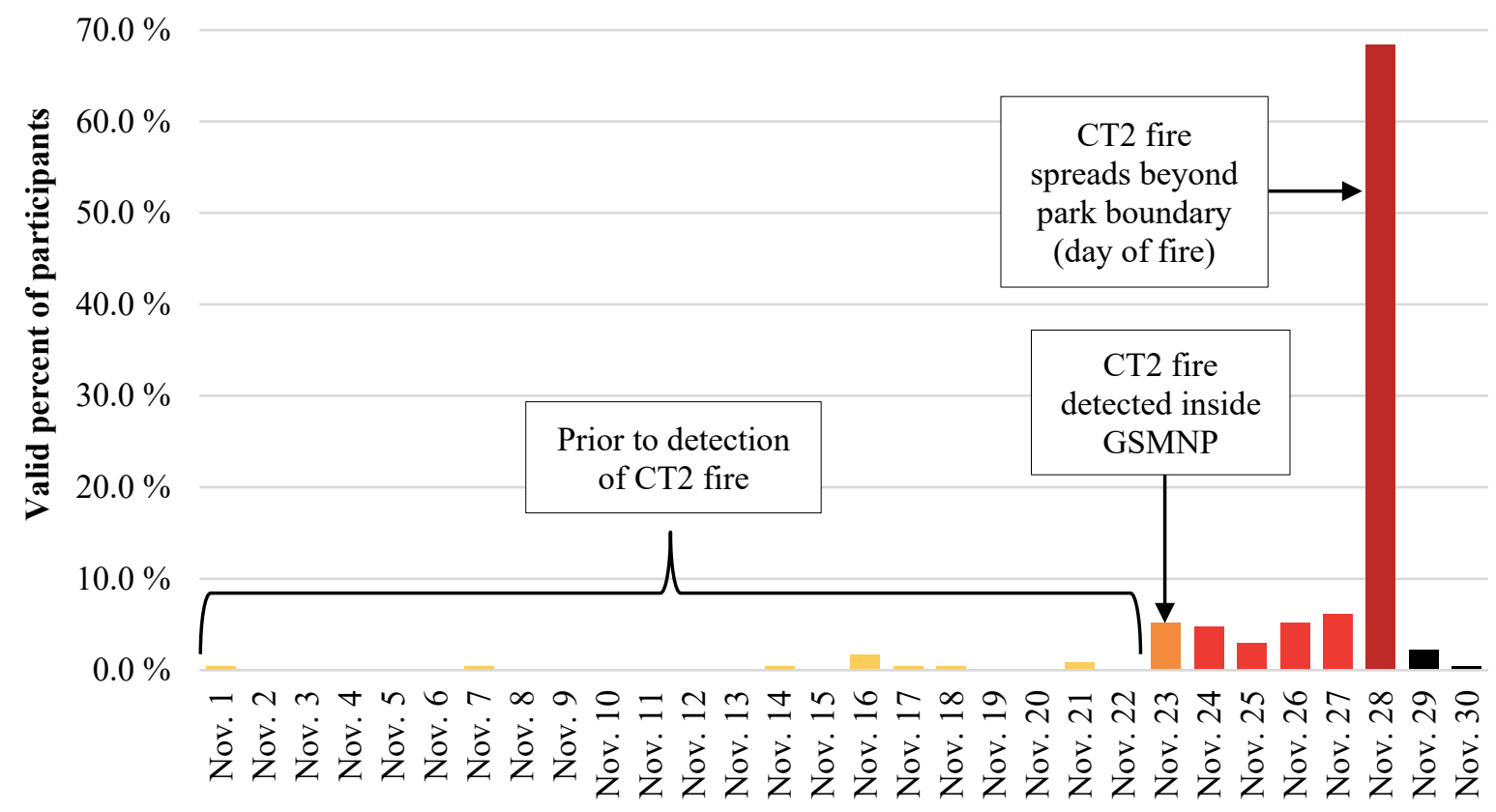

\section{Date of observation}

Figure 13. Timeline of when participants observed fire cues among those who observed them $(n=231)$. 


\subsection{Evacuation Decision and Risk Perceptions}

Participants were asked about their evacuation decision process, and their risk perceptions at the time their decision was made. Overall, the majority of participants decided to evacuate on the day the fire spread into Sevier County (November 28), and risk perceptions (namely the perceived likelihood that they or others might become injured or die as a result of the fire) were relatively high for all participants, especially the perceived risks posed to others. Risk perceptions were also higher among those who decided to evacuate than those who decided to stay, particularly with regards to personal impacts.

The large majority of participants, $82.0 \%(\mathrm{~N}=265)$, decided to evacuate in response to the Chimney Tops 2 fire (defined as leaving and travelling to a different or safer place). Of the 303 participants who provided a date for this decision, $4.3 \%$ made their decision on the day the fire was detected (November 23), $8.9 \%$ made their decision between when the fire was detected and when it spread to residential areas (November 24 to November 27), and the majority, $79.2 \%$, made their decision on the day the fire spread into Sevier County (November 28). In addition, 3.3\% made their decision the day after the fire spread (November 29 to November 30), and $4.3 \%$ reported that they made their decision before the fire on Chimney Tops 2 was discovered (November 7 to November 22; perhaps due to error). See Figure 14.

\section{Date of Evacuation Decision}

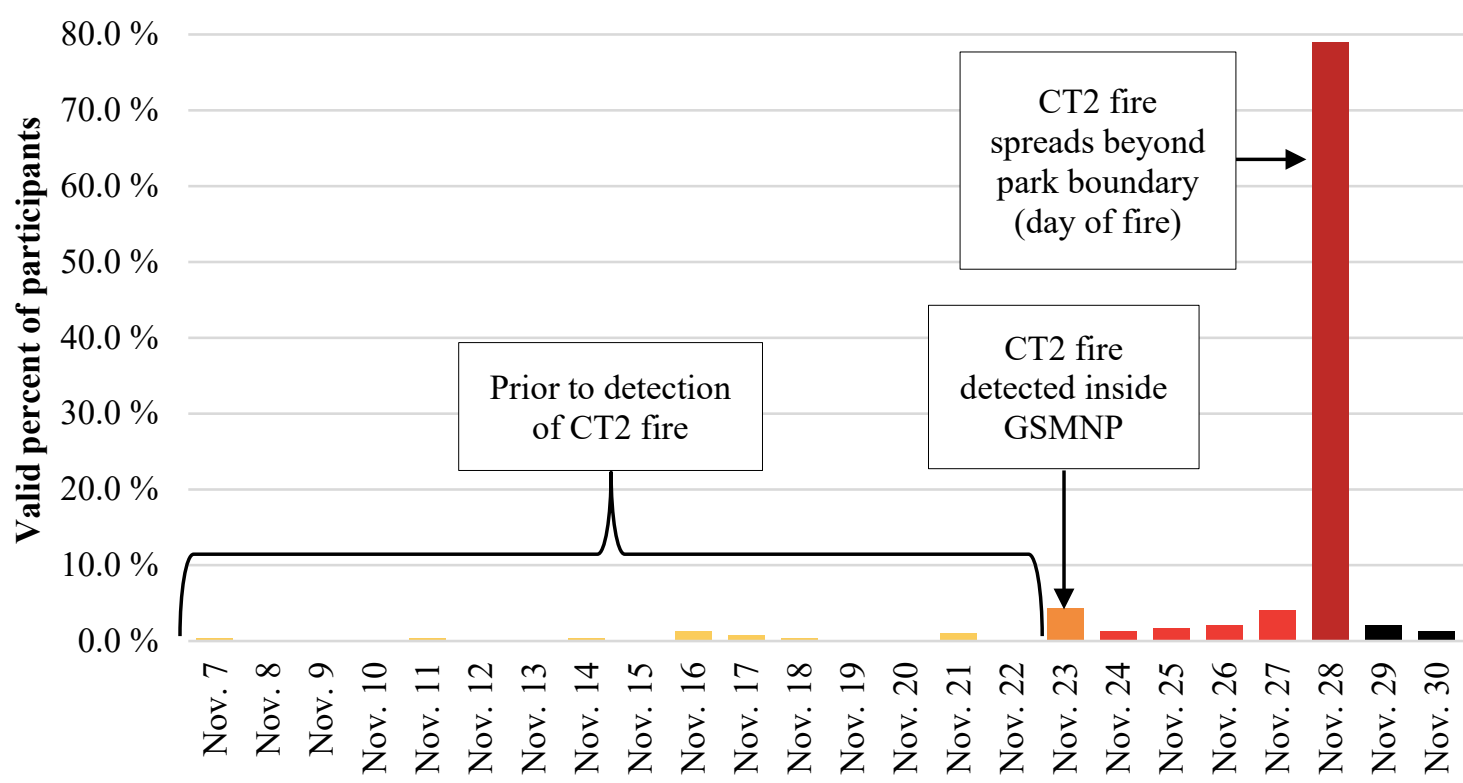

Date of decision

Figure 14. Timeline of when participants made their evacuation decision $(\mathrm{N}=303)$. 
Participants were then prompted to select a descriptor of their decision-making process. Of the participants (320) who provided their reasoning, $34.4 \%$ made the decision with their family, followed by $28.4 \%$ who made the decision by themselves. Next, $10.3 \%$ reported that they were following the instructions given by an authority, $8.8 \%$ made the decision with friends or neighbors, $3.1 \%$ decided to follow what others around them were doing, and only $1.6 \%$ followed a previously developed emergency plan. In addition, $13.4 \%$ of the participants responded "Other", often providing details on the fire or other cues they observed (such as seeing others evacuating) as a means of describing their decision process.

Next, participants were asked to rate their perceptions of risk (to themselves and to others) at the time of their evacuation decision. Risk perception was measured with four items, using a 1-5 scale where 1= "Not likely" and 5= "Extremely likely". Overall, participants perceived the likelihood of others being injured or killed to be higher than the likelihood of themselves being injured or killed (with means of 4.13 and 3.99 compared to 3.45 and 3.16, respectively). Although, the standard deviations for self-oriented risk perceptions were larger, indicating a greater diversity in responses compared to other-oriented risk perceptions. See Table 2 for response frequencies, and Figure 15 for a Box and Whisker plot of responses.

Table 2. Response frequency of risk perceptions at the time of evacuation decision.

\begin{tabular}{|l|c|c|c|c|c|c|c|}
\hline ITEM & $\begin{array}{c}\text { 1- Not } \\
\text { likely }\end{array}$ & $\mathbf{2}$ & $\mathbf{3}$ & $\mathbf{4}$ & $\begin{array}{c}\text { 5- Extremely } \\
\text { likely }\end{array}$ & Mean & SD \\
\hline I might become injured & $16.8 \%$ & $12.8 \%$ & $15.6 \%$ & $17.8 \%$ & $37.1 \%$ & $\mathbf{3 . 4 5}$ & $\mathbf{1 . 5 0}$ \\
\hline $\begin{array}{l}\text { Other people/pets/livestock } \\
\text { might become injured }\end{array}$ & $6.6 \%$ & $6.9 \%$ & $11.6 \%$ & $16.6 \%$ & $58.4 \%$ & $\mathbf{4 . 1 3}$ & $\mathbf{1 . 2 5}$ \\
\hline I might die & $25.8 \%$ & $12.4 \%$ & $15.5 \%$ & $12.4 \%$ & $33.9 \%$ & $\mathbf{3 . 1 6}$ & $\mathbf{1 . 6 2}$ \\
\hline $\begin{array}{l}\text { Other people/pets/livestock } \\
\text { might die }\end{array}$ & $9.3 \%$ & $7.8 \%$ & $11.5 \%$ & $17.4 \%$ & $53.9 \%$ & $\mathbf{3 . 9 9}$ & $\mathbf{1 . 3 5}$ \\
\hline
\end{tabular}

Comparing the responses between those who responded to this item who chose to evacuate $(\mathrm{N}=264)$ and those who chose to stay $(\mathrm{N}=54)$, it was found that those who decided to evacuate had markedly higher risk perceptions on all four items, particularly the perception that they might be injured (a mean of 3.38 vs. 2.07) or die as a result of the fire (3.69 vs. 2.24). Reflecting these trends, those who decided to stay more commonly responded that they were "Not likely" to experience personal injury or death $(42.6 \%$ vs. $11.7 \%$ and $51.9 \%$ vs. $20.4 \%$ ), and those who decided to evacuate more commonly responded that they were "Extremely likely" to experience personal injury or death $(38.1 \%$ vs. $11.1 \%$ and $42.0 \%$ vs. $11.1 \%$ ). See Tables 3-6 and Figure 15. 


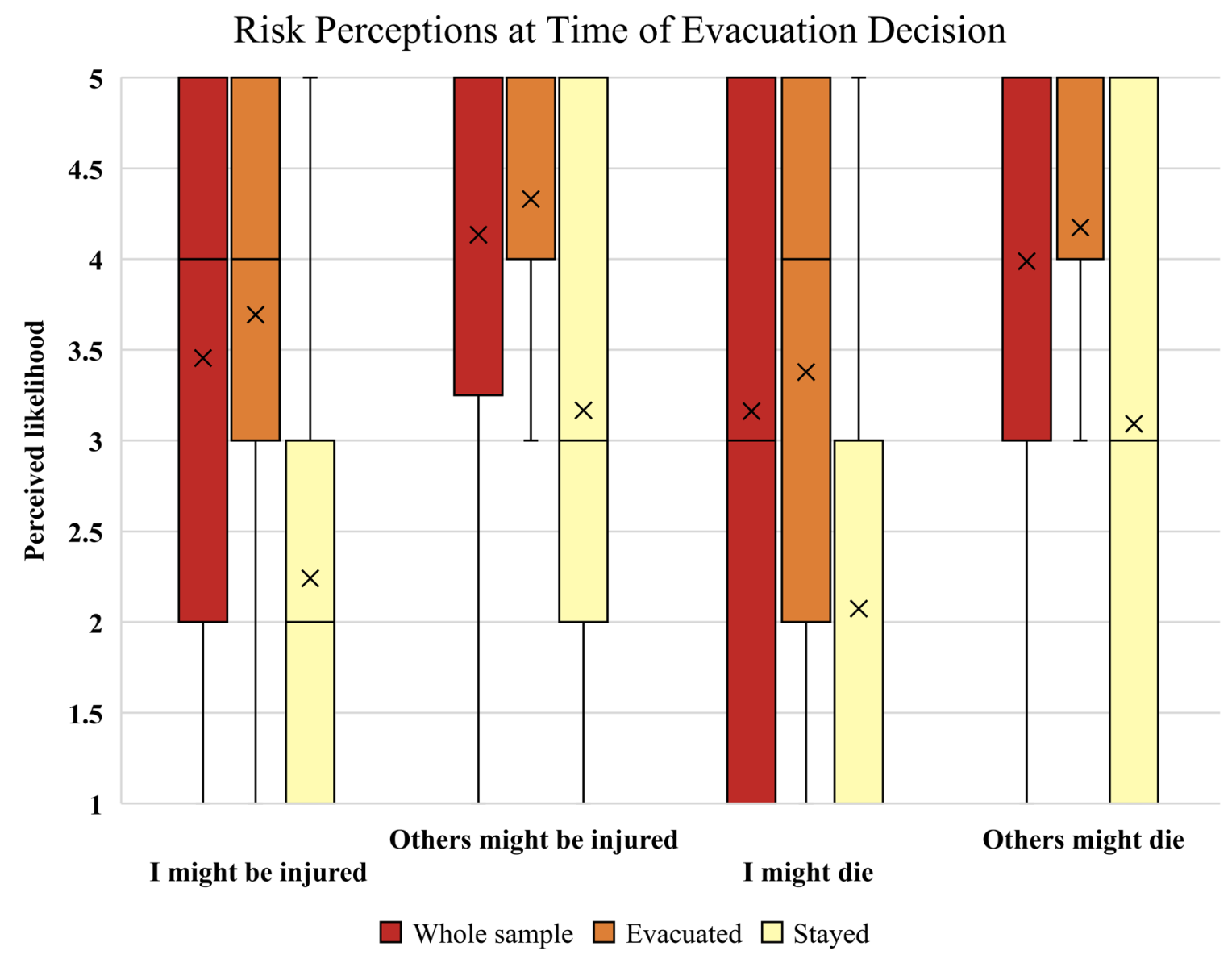

Figure 15. Box and Whisker plot of risk perception items for all respondents (red; $\mathrm{N}=318$ ), those who evacuated (orange; $\mathrm{N}=264$ ), and those who stayed (yellow; $\mathrm{N}=54$ ). (To interpret the Box and Whisker plot, the "x" indicates the response mean and "-" the response median. The shaded boxes represent the middle two quartiles of responses, and the lines the outer two quartiles). 
Table 3. Comparison of risk perceptions between those that decided to evacuate vs stay: personal injury.

\begin{tabular}{|l|c|c|c|c|c|c|}
\hline Group & 1- Not likely & $\mathbf{2}$ & $\mathbf{3}$ & $\mathbf{4}$ & $\begin{array}{c}\text { 5- Extremely } \\
\text { likely }\end{array}$ & Mean \\
\hline Decided to evacuate & $11.7 \%$ & $11.4 \%$ & $14.8 \%$ & $20.1 \%$ & $42.0 \%$ & $\mathbf{3 . 6 9}$ \\
\hline Decided to stay & $42.6 \%$ & $20.4 \%$ & $18.5 \%$ & $7.4 \%$ & $11.1 \%$ & $\mathbf{2 . 2 4}$ \\
\hline
\end{tabular}

Table 4. Comparison of risk perceptions between those that decided to evacuate vs stay: others injured.

\begin{tabular}{|l|c|c|c|c|c|c|}
\hline Group & 1- Not likely & $\mathbf{2}$ & $\mathbf{3}$ & $\mathbf{4}$ & $\begin{array}{c}\text { 5- Extremely } \\
\text { likely }\end{array}$ & Mean \\
\hline Decided to evacuate & $3.4 \%$ & $5.3 \%$ & $9.5 \%$ & $18.3 \%$ & $63.5 \%$ & 4.33 \\
\hline Decided to stay & $22.2 \%$ & $14.8 \%$ & $20.4 \%$ & $9.3 \%$ & $33.3 \%$ & 3.17 \\
\hline
\end{tabular}

Table 5. Comparison of risk perceptions between those that decided to evacuate vs stay: I may die.

\begin{tabular}{|l|c|c|c|c|c|c|}
\hline Group & 1- Not likely & $\mathbf{2}$ & $\mathbf{3}$ & $\mathbf{4}$ & $\begin{array}{c}\text { 5- Extremely } \\
\text { likely }\end{array}$ & Mean \\
\hline Decided to evacuate & $20.4 \%$ & $11.7 \%$ & $15.8 \%$ & $14.0 \%$ & $38.1 \%$ & $\mathbf{3 . 3 8}$ \\
\hline Decided to stay & $51.9 \%$ & $16.7 \%$ & $14.8 \%$ & $5.6 \%$ & $11.1 \%$ & $\mathbf{2 . 0 7}$ \\
\hline
\end{tabular}

Table 6. Comparison of risk perceptions between those that decided to evacuate vs stay: other may die.

\begin{tabular}{|l|c|c|c|c|c|c|}
\hline Group & 1- Not likely & $\mathbf{2}$ & $\mathbf{3}$ & $\mathbf{4}$ & $\begin{array}{c}\text { 5- Extremely } \\
\text { likely }\end{array}$ & Mean \\
\hline Decided to evacuate & $5.7 \%$ & $6.4 \%$ & $10.2 \%$ & $20.1 \%$ & $57.6 \%$ & 4.17 \\
\hline Decided to stay & $25.9 \%$ & $14.8 \%$ & $18.5 \%$ & $5.6 \%$ & $35.2 \%$ & 3.09 \\
\hline
\end{tabular}




\subsection{Evacuation Action and Main Rationales}

After describing their evacuation decision-making process, participants were asked what they ultimately did in response to the Chimney Tops 2 fire and why. The majority of participants in the sample (note: slightly more than the percent of participants who had decided to evacuate) ultimately evacuated, and most did so on the day the fire spread into Sevier County (November 28), often in response to fire cues and in fear of their or other's safety. The minority of participants who stayed in place most commonly did so because they were not ordered to evacuate or to protect their property. The number and types of preparatory actions taken prior to evacuation (e.g., evacuation delay) were also measured.

The majority of participants in the sample (86.7\%) evacuated in response to the fire. These participants $(\mathrm{N}=280)$ were then asked to provide the date of their evacuation. Of those who provided dates, $4.2 \%$ evacuated before the Chimney Tops 2 fire was detected (November 7 to November 22), $3.4 \%$ evacuated on the day the fire was discovered (November 23 ), $8.4 \%$ evacuated between when the fire was discovered and when it spread to residential areas (November 24 to November 27), the majority (79.4\%) evacuated on the day of the fire (November 28), and $4.6 \%$ evacuated after the fire spread began (November 29 to November 30). See Figure 16.

\section{Date of Evacuation Action}

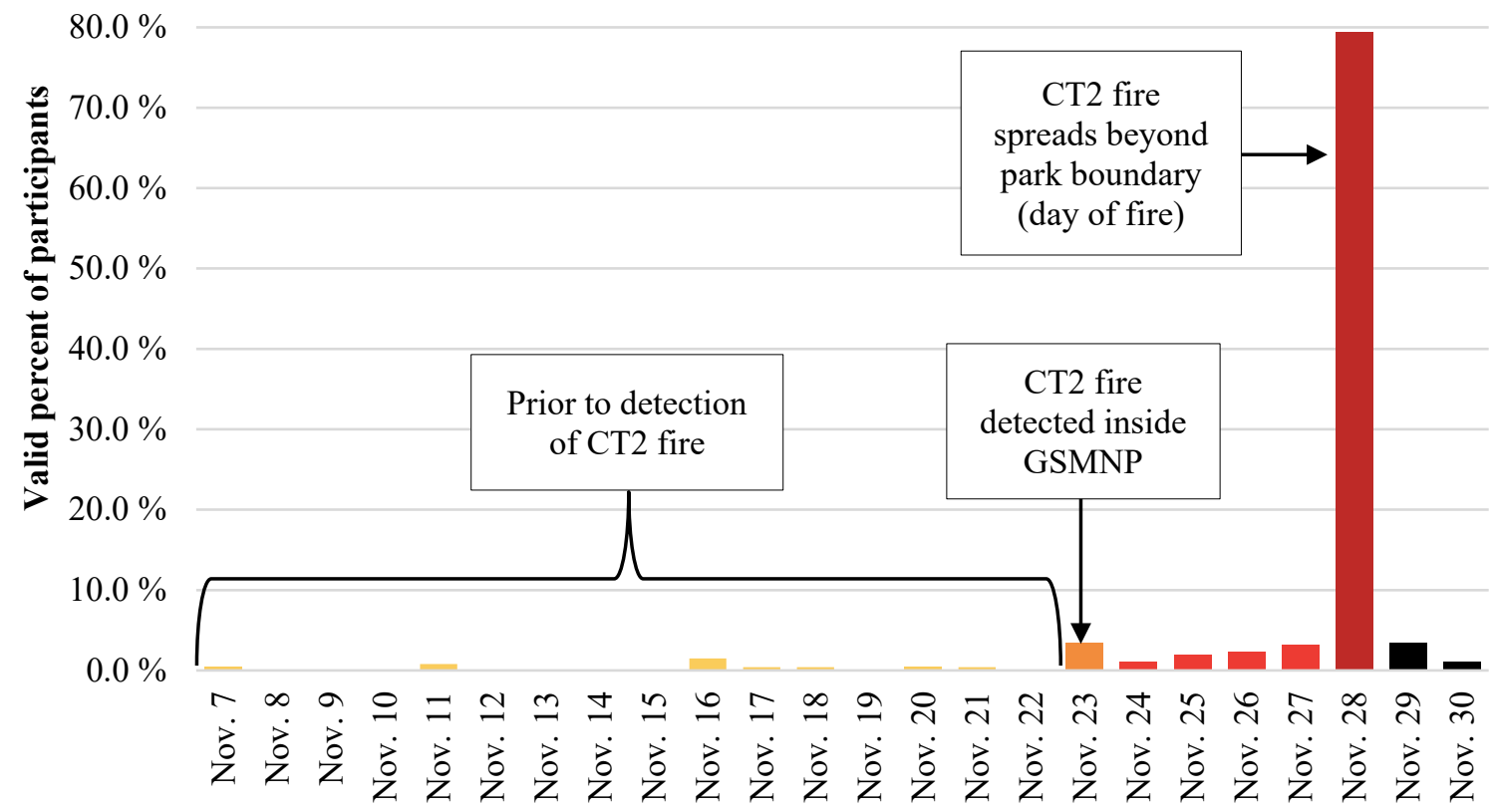

\section{Date of action}

Figure 16. Timeline of when participants took evacuation action among those who evacuated $(\mathrm{N}=262)$. 
Participants who ultimately evacuated $(\mathrm{N}=280)$ were then prompted to provide their main reasons for evacuating as a select-all item with several options. Most commonly, $81.4 \%$ of participants who evacuated reported that they acted after they observed some kind of fire cue. More specifically, $77.5 \%$ indicated that they evacuated because they saw, heard, or smelled the fire, $26.8 \%$ did so because they were overwhelmed by heat or smoke, and $15.5 \%$ had discovered that their property caught fire (note that participants were able to select more than one item).

Next, $42.1 \%$ of participants indicated that they evacuated because they were afraid or felt in danger for themselves, $41.8 \%$ were afraid for others, and $28.2 \%$ reported that they were afraid for pets or livestock. In addition, $25.0 \%$ indicated that they evacuated because they were advised to do so by a friend or family member, followed by $17.9 \%$ who evacuated based on information about the fire (such as location, intensity, etc.) and $15.7 \%$ who evacuated after directly observing others evacuate (i.e., seeing neighbors leave). $11.4 \%$ evacuated because they received an evacuation order from police, fire, or emergency officials, $11.1 \%$ who received an evacuation advisory from police, fire, or emergency officials, $7.1 \%$ who were ordered to evacuate by a friend or family member, and $6.8 \%$ who observed others evacuating through the media (television, radio, or social media). Lastly, several participants added additional reasons for evacuating under "Other", including high winds $(1.4 \%)$ and power outages $(0.7 \%)$. See Figure 17.

\section{Main Reasons for Evacuating}

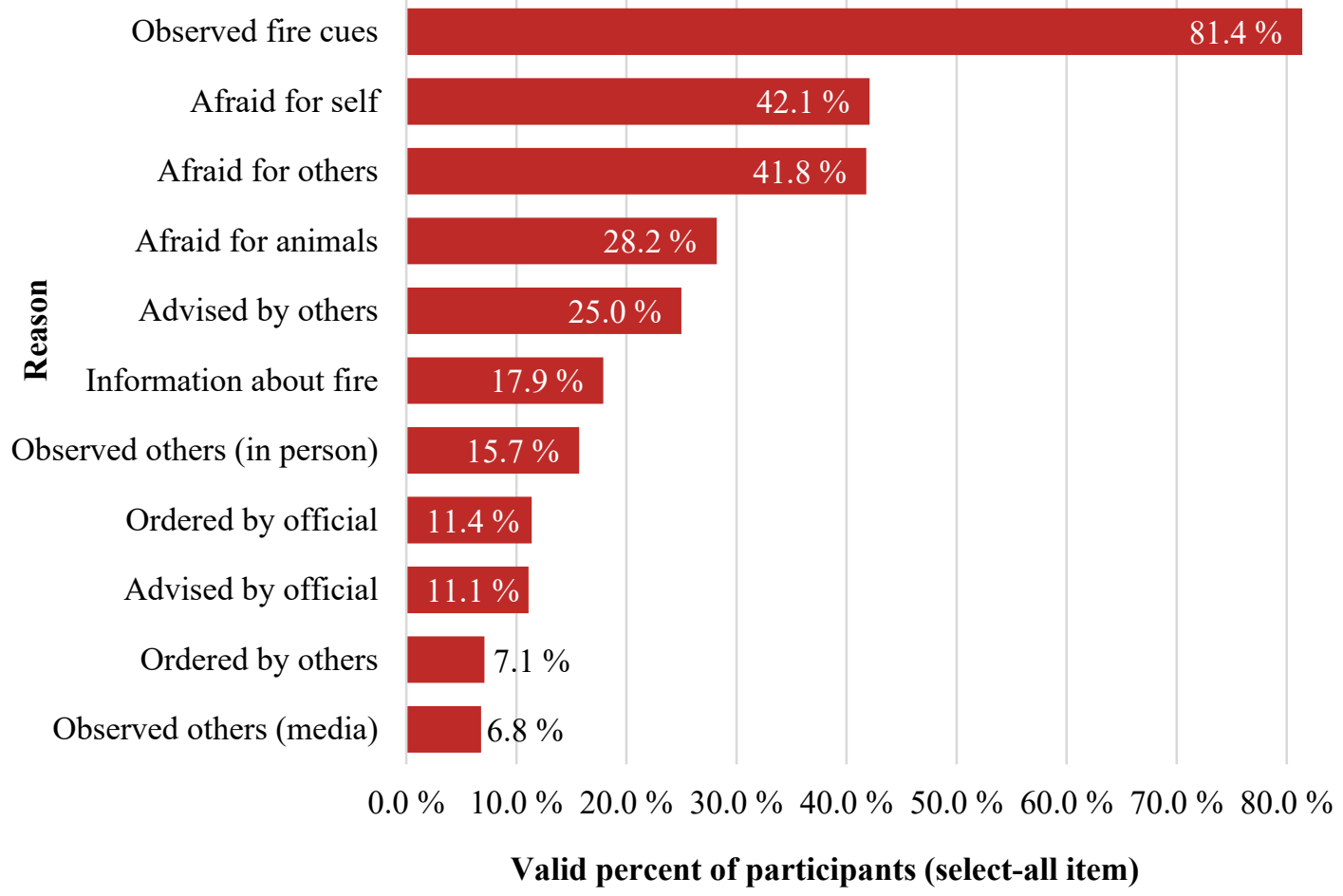

Figure 17. Main reasons for evacuating among those who evacuated $(\mathrm{N}=280)$. 
Participants who ultimately evacuated $(\mathrm{N}=280)$ were also asked to select from a provided list any preparation actions they took prior to evacuating which might have delayed their movement to safety. Most commonly, $57.5 \%$ reported that they packed belongings before they left, followed by $36.4 \%$ who took time to communicate their plan to others, $31.4 \%$ secured their home, $28.9 \%$ prepared family members or themselves (e.g., getting dressed, using the bathroom), $28.2 \%$ identified an evacuation destination, $25.7 \%$ informed others of danger, $23.2 \%$ reunited with or attended to animals, and $22.1 \%$ planned their evacuation route. In addition, $16.4 \%$ reunited with family members, $13.6 \%$ asked other people what they were doing or planned to do, $13.2 \%$ helped others prepare, $11.4 \%$ reunited with people outside of their family (e.g., friends, neighbors, coworkers), $8.6 \%$ prepared their property (e.g., put water on the house/vegetation/landscape), and $3.2 \%$ secured their business.

Lastly, $5.0 \%$ of participants (14) who evacuated selected that they "did nothing" prior to evacuating (i.e., left immediately), and an additional $4.6 \%$ of participants shared under "Other" that they had no time to do anything but grab a few items and flee. For this select-all item, the number of actions taken prior to evacuation were also summed for each participant. These sums ranged from $0-11$ preparation actions in total, with a mode of one, and a mean response of 3.32 actions $(\mathrm{SD}=2.59)$. See Figure 18.

\section{Number of Actions Taken Before Evacuation}

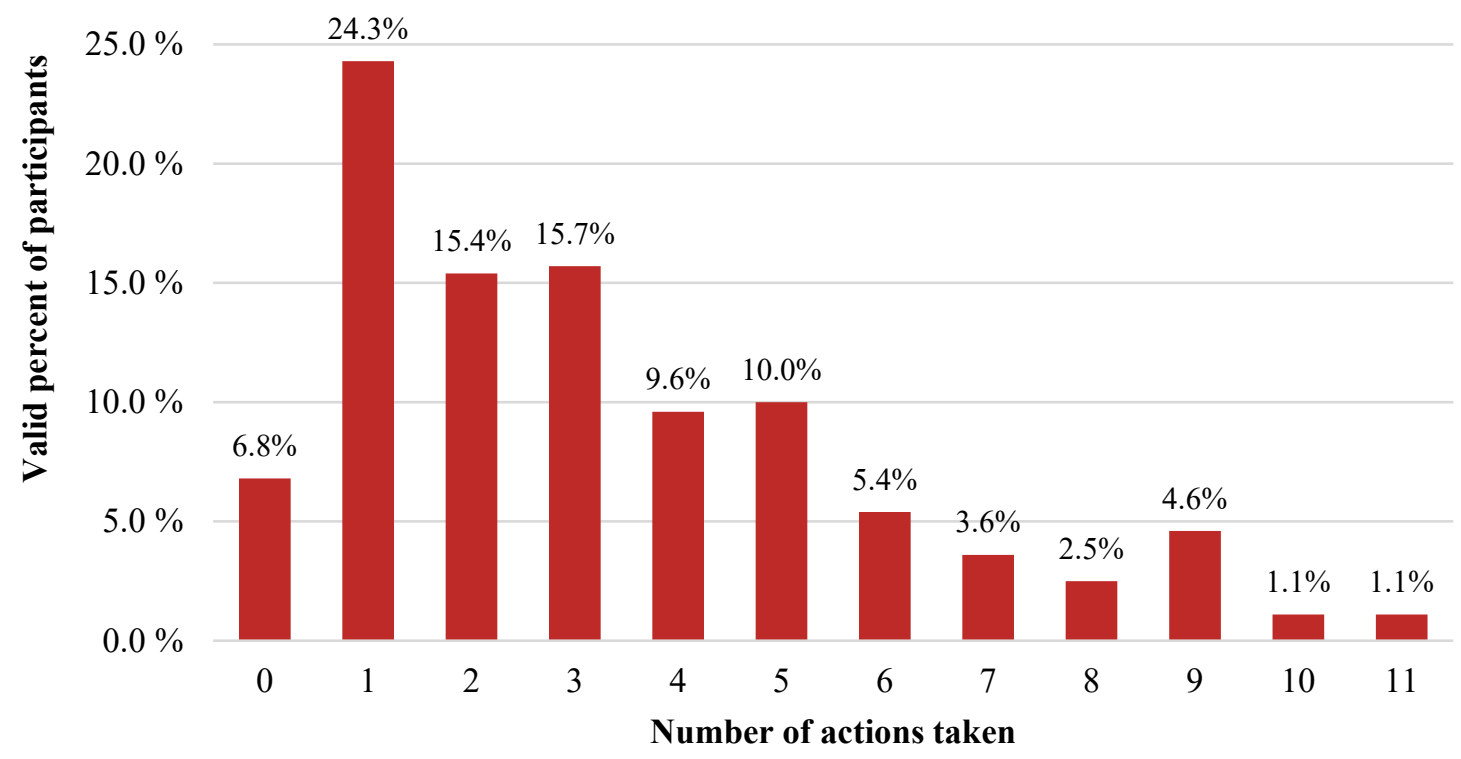

Figure 18. Number of actions taken prior to evacuation among those who evacuated $(\mathrm{N}=$ 280). 
The minority of participants who stayed in place $(\mathrm{N}=43)$ were asked their main reasons for doing so using a select-all item. Most commonly, $41.9 \%$ of these participants reported that they stayed because they were not ordered to evacuate, $30.2 \%$ stayed to defend or protect their property, $25.6 \%$ stayed because they did not receive any evacuation messages or warnings, $23.3 \%$ felt it was too late or too dangerous to evacuate, $18.6 \%$ felt it was safer to stay in place, $18.6 \%$ did not believe they were in an area at risk of wildfires, $16.3 \%$ stayed to take care of animals, and $11.6 \%$ stayed because they directly observed others staying behind (i.e., seeing people in their neighborhood). In addition, $7.0 \%$ stayed to do their job, $4.7 \%$ stayed to take care of a person (or persons) who were unable to evacuate, $4.7 \%$ were physically unable to evacuate, $4.7 \%$ did not believe that there would be a fire, $4.7 \%$ did not know anything about the fire occurring, $2.3 \%$ observed others staying through the media (e.g., television, radio, social media), and $2.3 \%$ did not have the resources to evacuate (e.g., money or a vehicle). Notably, $11.6 \%$ of those who stayed in place specified that they could not evacuate because their routes were blocked under an "Other" comment. See Figure 19.

\section{Main Reasons for Staying in Place}

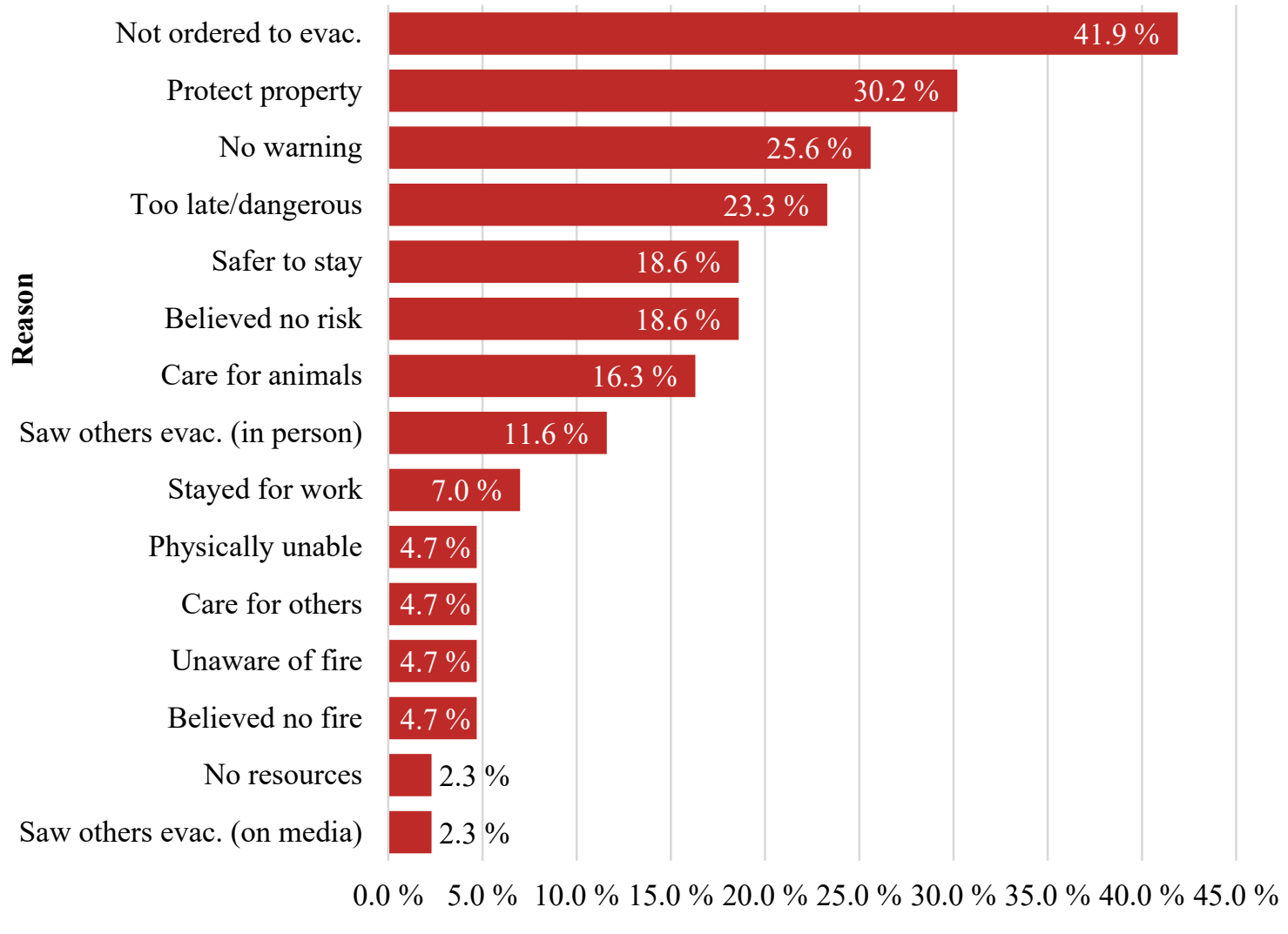

Valid percent of participants (select-all item)

Figure 19. Main reasons for staying in place among those who stayed in place $(\mathrm{N}=43)$. 


\section{Thematic Analysis of Survey Comments}

At the end of the survey, participants were invited to share any additional comments or thoughts they had related to the Chimney Tops 2 fire. These comments were optional and freely offered. In order to summarize their content, comments were coded in adherence to a codebook developed using the thematic analysis methods outlined by Braun and Clarke (2006) [16]. While many comments elaborated on responses already captured by the survey, many of them were rich in content and provided expanded insight into participants' experience of the fire and evacuation.

Four main themes into which codes were structured were identified. The first theme related to the information respondents received during the fire event that alerted them to danger or communication failures that prevented them from receiving needed information. The second theme related to experiences with the evacuation itself, including descriptions of individuals' evacuation process, actions they took, and challenges they faced (including pets and mobility issues). The third theme related to experiences in the aftermath of the fire, including recovery efforts and suggestions for improving preparedness for future fire events. The fourth theme then included participants' more general comments about the fire event.

\subsection{Theme 1 - Evacuation Information and Communication}

A total of 102 respondents contributed comments related to different aspects of the information or communication they received (or did not receive) about the fire. We divided these comments into two main sub-themes: the information that individuals received surrounding the fire event (including those from social sources, official sources, the media, and fire cues) and communication failures (including participants who received no warnings, experienced technological issues, felt the warnings they received were sent too late to be helpful, or received what they perceived to be misinformation).

Information Sources: 64 participants discussed the sources where they received information that alerted them to the fire or kept them updated on the fire or the need to evacuate. These comprised of three sources and cues from the fire itself (note that participants could mention more than one source in comments, so the sum of these categories exceeds 64).

Social: The most common information sources mentioned by participants ( 21 individuals) were social contacts such as relatives, friends, and neighbors. This information was typically received via a phone call, text message, social media, or inperson interactions. According to one respondent, "It was only a family member coming home from work ... that alerted me to the fact that the flames were 1.5 miles away." A few of these participants received information from relatives living in states as far away as Georgia, Florida, and Texas who had seen coverage of the fire on social media or the news and alerted them to the danger.

Official Sources: Some respondents (10) noted receiving information from official sources, including police or fire personnel and government officials. This information was received through a variety of channels, including posted updates, phone calls, 
and in-person interactions (such as door-to-door notices). Two participants also noted that they were alerted to the evacuation via loudspeakers. However, in both instances these warnings were insufficient on their own and were only heard due to specific circumstances (e.g., they happened to be by the door).

Media: A few participants (4) mentioned in their comments that they received information about the fire event from the news media. All of these comments stated that the news informed them of high wind warnings in the area, but only half (2) specifically mentioned that the news reports discussed the potential for fires to spread due to the wind.

Fire Cues: Participants (35) also mentioned being alerted to the immediate danger of the fire when they observed cues from the fire itself, including smoke, ash, flames, and the glow of the fire. Often (28), fire cues served as the first warning that individuals received in the absence of warnings from official, social, or other sources, e.g., "My first warning was my neighborhood being engulfed in flames."

Miscellaneous: There were also some individuals (7) who shared more general comments that reflected the information received without specifying the source, which were coded as miscellaneous (e.g., "...we received a phone call that there was a fire in the valley", "... I had no idea how very close the fire was to our home until I saw the pictures on Facebook" (no Facebook page specified).

Communication Failures: A portion of participants (88) also discussed what they perceived to be communication failures that resulted in receiving no information, late or insufficient warnings, or what was described as misinformation. These issues comprised of four main concepts.

No warning: Several respondents (62) shared in their comments that they received no warnings from official, social, or other sources or did not receive necessary information that made them realize they were in danger. Some of these participants (13) indicated that fire cues were the first indication that they were in danger. One participant stated: "There was no warning about the fire NOT being contained. I saw fire on the mountain behind my job and decided to leave." Of these individuals, 19 participants specifically stated that they did not receive a warning from an official source, implying that for these individuals, an official warning was the expected channel to inform them of wildfire risks or evacuation.

Technological issues: Some participants (22) who reported communication failures discussed technological issues that interfered with their ability to receive or seek information about the fire and evacuation, namely that they were unable to access websites or receive/make calls due to congested internet and phone channels or power outages.

Late warning: A few respondents (15) indicated that the warnings they did receive were sent too late to effectively guide their decision-making, in that information was not received until after the fire had reached their area or they had already made the 
decision to evacuate. For example, one participant stated that the fire reached their property around 7:00 pm but that they did not receive an evacuation notice until 9:00 pm, at which time they had already evacuated to a relative's residence. Some participants also reflected the sentiment that the late arrival of warnings contributed to the dangerous nature of their evacuations, with one stating: "When we finally got the news to leave our home it was almost to [sic] late. There was really no way we could get out."

Misinformation: Lastly, some individuals (22) describing communication failures where they felt the information they received was inaccurate. Most commonly, this was where respondents were instructed to stay in place by the media or officials (either because the fire was not a threat overall or because their location was not yet at risk and therefore did not need to be evacuated) and later had to evacuate when the fire reached their neighborhoods or homes. Participants also felt that they received inaccurate information regarding evacuation routes and road closures.

\subsection{Theme 2 - Evacuation Process}

A total of 103 respondents contributed comments related to their experiences with the evacuation itself. These comments comprised of six main sub-themes, including feelings that the process was traumatic and/or difficult, the assistance they received or felt they should have received, actions they took, descriptions of their evacuation process and challenges they faced (such as pets and mobility issues), and their preparedness or awareness of fire risks on the day the fire spread into Sevier County (November 28).

Awareness: Some participants (34) discussed their awareness, or lack thereof, of fire risks on the day of the fire or the area in general prior to the fire. These participants were generally unaware of fire risks on the day or were surprised by how quickly it spread although some were aware of the conditions that made fire spread more likely and described "keeping an eye" on conditions and the fire's growth. Most of these participants (34) mentioned that they were aware of nearby fires or high-risk conditions, but most of these (22) did not believe that they were at risk of being personally affected by the fire (e.g., "We were not concerned because we had been exposed to the smoke for the past few weeks"; "Even though we could see fire in the distance we had a misdirected idea that we were safe."). A few participants (5) also stated that they were insufficiently prepared for the evacuation, and two individuals commented on how unaware of danger and unprepared for evacuation other community members were.

Evacuation actions: Another common concept (mentioned by 51 individuals) within the area of evacuation experiences was the actions that they took during the fire event, including seeking information, evacuating, and defending in place.

Seeking information: A number of participants (23) described seeking out information to fill in perceived gaps in information and/or to become more informed of the fire and evacuation orders. These participants sought information by calling the 
fire department, police department, and Mayor's office, listening to news and radio stations, and monitoring online sources such as websites and social media.

Evacuation decision: Some participants (32) mentioned deciding to evacuate based on observed fire cues and being notified of the danger by neighbors, friends, or family. This process included identifying evacuation routes and safe destinations before leaving. One participant, who evacuated to an open parking area with no surrounding trees, later used by the local fire department to house other evacuees, said: "We stayed all night while the fire burned around us, but we were safe."

Defending home: A small number (5) of respondents mentioned taking actions to defend their property. This action involved using sprinkler systems to douse structures and/or fighting spot fires on their property until firefighters arrived to assist.

Evacuation process: Some participants (28) generally described their evacuation process in their comments. These participants described actions they took immediately prior to evacuation (e.g., gathering family members, important belongings and documents, and pets), delays and interruptions they encountered such as being kept at work and needing to return home before evacuating as well as general descriptions of their movement to safety (routes, destination, etc.).

A number of these participants (23) also specifically described the last-minute planning and preparing directly prior to their evacuation, such as discussing plans with family, grabbing valuables, and warning or calling others. These comments were often connected to the rushed, last-minute nature of their evacuation. Some also described the conditions that influenced or resulted in their last-minute preparations, for example: "The winds were so fast it made it difficult to prepare."

Other (6) participants discussed difficulties in evacuating pets, including getting back home to get pets, gathering pets, or having to leave pets behind. Five of these participants were not home as the fire approached their homes or had evacuated due to smoke but left pets behind because they did not believe their homes would be affected. One respondent was not aware of the fire's proximity to their home and did not have time to collect all of their pets before evacuating.

A few participants (7) also addressed challenges with mobility during the evacuation process. Some of these respondents received assistance during the evacuation (e.g., being taken to the hospital after having a heart attack, evacuating the elderly from their homes). Two respondents mentioned that they ultimately did not evacuate because they did not want to leave an immobile person (a neighbor and a relative) behind.

Evacuation assistance: Participants also discussed the assistance they received or did not receive during their evacuation. Approximately half (10) reported that they received needed assistance, including help with clearing roads, medical assistance, rescuing pets, evacuating those with mobility issues, and defending structures. Sources of this assistance included neighbors, the National Park Service, fire, police, and emergency personnel. 
Other respondents (13) noted that they could have used additional assistance, including physical presence of emergency personnel during the evacuation. Some participants (5) mentioned requesting assistance but were unable to receive it (e.g., via the 9-1-1 system or in-person assistance with firefighting or evacuation).

Difficult: One of the more common sentiments that participants shared (40 individuals) was that their evacuation was difficult or dangerous, largely due to the late nature of their evacuations. Participants described injuries sustained during the fire (3), impassible or obstructed routes blocked by debris, downed power lines, flames, etc. (21) or traffic jams (4), low visibility due to smoke (4), and being surrounded by flames as they evacuated (25).

Traumatic: Related to the aforementioned difficult evacuation conditions, some participants (28) reflected that their evacuation experience was scary, harrowing, or traumatic. For example, one participant described their evacuation as follows: "We drove through flames blowing across the roads three times before reaching the bottom of the mountain. [It was] The most terrifying experience of my life." A number of participants also reported calling family members and loved ones to say their goodbyes as they drove through the fire to evacuate.

\subsection{Theme 3 - Post-Event Impacts and Recovery}

74 participants contributed comments about the aftermath of the fire, which were grouped into five sub-themes related to lasting personal impacts, feelings of gratitude, recovery efforts, reentry, and suggestions for improving preparedness for future fire events.

Personal impacts: Participants (33) discussed personal impacts from the fire, including health complications, loss of friends, family, or loved ones, loss of one's home or business, and difficulty recovering mentally from the event. Several reported that they lost everything they owned. Others described the lasting trauma they still endure, such as: "I was in fear for my life and still to this day have only traveled the Spur [local road] once."

Gratitude: After the fire event, participants (18) expressed gratitude toward or commented on the good job that authorities, fire and police personnel, and the Tennessee Division of Forestry did to handle the fire event. These efforts were described as "valiant", "untiring", and "helpful". Others expressed gratitude in general comments that mentioned being personally lucky or blessed to have survived or avoided more serious damages (i.e., "it could have been worse").

Recovery: Some participants (20) discussed recovery in their comments, including the process of rebuilding one's home, the community at large, or the local economy as well as post-fire information and post-fire assistance. Two participants discussed the long-term impact the fire had on the entire area, saying "[...] the town of Gatlinburg really was hit hard," and "Gatlinburg is having a long hard recovery economically. " Additionally, a portion of respondents (8) discussed assistance they received, or lack thereof, after the fire.

Reentry: Of those who discussed reentry after the evacuation (9), several mentioned that they were unable to return to their homes and lacked information about the status of their home or 
pets that were left behind. Others were displaced for prolonged periods of time until their houses were rebuilt.

Suggestions for improvement: Some participants (19) reflected on issues they encountered during the fire and offered suggestions to help prevent future fires of similar magnitudes or mitigate losses. These suggestions included additional training for emergency personnel, improvements to the emergency communication systems, more focus on mitigation actions in national parks, increased transparency of the situation (including fire risks and fire progression), and improvements to evacuation routes (e.g., clearer signage, road paving and maintenance, and traffic light updates).

\subsection{Theme 4 - General Comments}

Lastly, 54 participants provided general comments about the fire event, expressing both frustration and support towards emergency officials at various levels of government and themselves. Frustration was expressed around event management, timing for warnings and evacuation, issues with evacuation routes, and overall preparedness of communities for this type of event. While less common, support was also expressed to emergency officials: a few participants mentioned the complexity of the event, calling it the "perfect storm" that caused conditions outside of officials' control (namely the high winds and dry conditions) that made it nearly impossible to manage. One participant stated: "We believe firefighters did the best they could under very difficult and unpredictable conditions. Nature can be tough!". 


\section{Summary of Findings and Recommendations}

The following sections summarize the findings and associated recommendations from the survey and thematic analysis of comments, including prior awareness of fire risks among participants, warnings and fire cues received, and evacuation decision-making and responses to the evacuation process itself.

\subsection{Prior Awareness and Preparation}

Participants in our sample were on average unaware of wildfire risks in their area and were often unprepared for wildfires prior to the Chimney Tops 2 event. Over half of the sample $(55.7 \%)$ took no fire preparation actions prior to the wildfire, and very few had evacuation plans $(18.3 \%)$ or personal experience with evacuations $(5.0 \%)$. The thematic analysis of survey comments similarly showed a lack of awareness of fire risks and advanced preparation; some participants $(\mathrm{N}=34)$ shared that they were aware of nearby fires or highrisk conditions but did not realize it could impact them personally, and most of those who discussed preparation $(\mathrm{N}=23)$ described last-minute packing as the fire approached their homes.

\section{Recommendations:}

- Improve fire awareness and preparedness in WUI communities

Improved fire awareness and evacuation preparedness, such as having a family evacuation plan, has been found in previous research to increase the likelihood of wildfire evacuation $[17,18]$. These preparatory steps can be especially important for communities that are at risk of wildfire but do not have previous experience with wildfires or evacuations, where a lack of awareness or preparation may contribute to lower evacuation rates or more difficult, last-minute evacuations. As observed in our findings, participants shared that they were often aware of a fire occurring in the area or observed fire cues (particularly smoke), but initially dismissed this information either due to a lack of risk awareness or official warnings from authorities.

Potentially because this population was fairly unfamiliar with wildfire threats, outreach material could be developed to improve wildfire awareness and evacuation knowledge among both residents and vacationers, and help members of the public be more vigilant to risks like rapidly changing fire conditions. Officials can also collaborate with other community-based efforts, for example the National Fire Protection Association's Firewise program, to disseminate these materials. As another option, evacuation drills could help to improve community preparedness for what to do in the event of a wildfire (e.g., become familiar with emergency routes and plan their preparation actions and destinations in advance) and likely result in a more prompt and coordinated public response to evacuation notices. 
Make wildfire risks local and personal

From the survey results and comments, it was observed that when participants were made aware of a nearby wildfire threats via warnings or fire cues they often felt that it would not impact them personally, and risk perceptions for "others" were consistently higher than those for the self. While self-protective responses like these are fairly common in response to threats (e.g.; "the danger will impact other people, but not $m e$ "), research has found that protective behavior is more likely to result from hazards that are perceived as personally relevant [19], in particular when individuals also believe that the protection action will be effective [20]. As a result, it could be beneficial to develop outreach programs that focus on personalizing local wildfire threats and in turn assist individuals in creating personal preparation and evacuation plans to increase their sense of efficacy. Additionally, warning efforts could be expanded to further personalize wildfire threats during an imminent event; for example, see Sutton and Kuligowski, 2019 [21] for message templates for short message alerting systems that aim to increase risk perception of households in disaster events.

\subsection{Warning Content, Timing, and Fire Cues}

The majority of survey participants $(77.3 \%)$ reported that they did not receive any warnings about the wildfire prior to deciding to evacuate, and $84.0 \%$ did not remember receiving any official warning. Those that did receive a warning more commonly got them from social sources (e.g., family, friends, or neighbors) and typically received their first warning on the day the fire spread into Sevier County (November 28). Participants also reported that the warnings they received were most commonly about the wildfire's location (71.2\%), although they often lacked necessary information about the need to evacuate or which routes to take. In their comments participants also described specific communication issues, such as lack of access to information due to power outages and warnings arriving too late to aid in decisionmaking (See Section 4.1).

Meanwhile, nearly three-quarters of the sample observed fire cues that provided them with information about the wildfire and for some their first warning of the danger. These cues included flames, embers, smoke, winds, and heat, and some participants also noted that they commonly observed falling ash and an orange or red glow in the sky. The majority of participants who observed fire cues $(68.4 \%$ ) did so on the day of the fire (November 28 ), although a few participants commented that they had seen or smelled smoke in the area for as long as several weeks before the fire spread into the Sevier County. 


\section{Recommendations:}

Issue early, consistent warnings to the public

Due to technical and communication difficulties noted in other event reports [11] official warnings in relation to the Chimney Tops 2 fire appeared to be disseminated at a later than ideal time, and a lack of official warning or timely warning appeared to be a common issue shared in survey comments. Therefore, officials are urged to provide as timely and unified communications to the public as possible. A method to assist in this effort is by identifying trigger buffers or boundaries for WUI communities during evacuation planning. Trigger buffers are geographical locations on the landscape that, once crossed by fire, would trigger a community's evacuation [22]. These buffers can be determined by: 1) identifying likely fire scenarios that can impact a WUI community (and their corresponding fire spread rates); 2) estimate the time necessary for the community to evacuate, taking into account likely household delays and actions; and 3) based on the assumed fire spread rate of each likely fire scenario, identify the community's geographical boundary that would allow sufficient time for the full community evacuation. Planning in this way can assist officials in making important decisions during a fire event on who and when to evacuate populations at risk to ensure sufficient time is given. Then, as WUI communities grow, consistently evaluating and updating these plans may also be needed.

* Fire and evacuation information should be disseminated on various, accessible channels, which the public is made aware of in advance of an event

Some survey comments provided details on specific information access issues, such as a lack of access to televisions or phones due to loss of power, and emergency lines (9-1-1) being overwhelmed with calls. An improvement to communication systems would be to invest in alternative means of communicating real-time alerts, such as WEA, TV, official websites and social media accounts, and local radio channels, and also identifying the communication modes that could still be used during longer-term power outages (e.g., community warning sirens or Ham radios). Education of the local public could then increase awareness of emergency plans and how to obtain information in case of power loss or communication failures, such as utilizing battery-powered radios or household weather radios.

* Disseminate clear, accurate, and specific warnings from trusted sources and channels, and other tips from emergency communication research

Our findings indicated that the most commonly trusted information source in emergencies was police and fire departments (48.4\%). In previous communication research, it has been found that receiving a warning from a credible or official source can increase evacuation compliance, as well as issuing repeated warnings $[5,6,10]$. These and other recommendations from communications research on creating effective warning warnings messages can be found in Sutton and Kuligowski (2019) 
[21], Sorensen (2000) [23], and The National Academies of Sciences, Engineering, and Medicine report on emergency alert and warning systems (2018) [24].

- Evacuation notices should provide critical information including time left to evacuate, route status, and suggested routes

Of the warnings and information that participants received the most common content was the location or severity of the fire, although many participants felt they lacked crucial information such as if or when they should evacuate and route status. Since only $22.1 \%$ of survey participants who evacuated indicated that they planned their evacuation route beforehand, this could indicate that the vast majority of evacuees simply drove on a selected road until they encountered emergency personnel who provided them with further instruction. Planning how to most effectively provide this information via messages or signage could help to reduce confusion associated with traffic and road closures during early stages of an evacuation and help individuals quickly select the safest routes away from danger. Another option is to develop and provide real-time information on route status by partnering with mobile applications such as Waze. In this way, it could be possible to provide timely and accurate route information to evacuees even during dynamic situations.

\subsection{Evacuation Decisions and Process}

The majority of our participants either decided to evacuate (83.1\%) or actually evacuated from the Chimney Tops 2 fire (86.7 \%). Of these, the majority (79.2\%) also evacuated on the day of the fire, most commonly in response to fire cues and fear for their own or other's safety. Participants also often sought information, chose evacuation routes, and decided to evacuate on their own. As a result, many participants described a harrowing and last-minute evacuation process that included driving through dangerous conditions. Then, for the minority of participants who did stay in place, the most common reasons for doing so were a lack of warning or official evacuation orders, or to protect their property.

\section{Recommendations:}

\section{* Provide focused assistance to vulnerable populations}

Among those who stayed, a proportion reported that they were either unable to evacuate due to blocked routes, felt that it would be too dangerous to evacuate, or were physically unable to evacuate due to themselves or others needing physical assistance. Communities should identify their vulnerable populations in advance (e.g., people with mobility impairments, non-English speakers, older individuals, those who lack financial resources or lack transportation, homeless communities, or those in isolated locations or without access to communication technologies) and should consider creating plans to provide focused, active assistance to improve evacuation rates and safety. 


\section{* Advanced planning for pets and livestock}

In addition, the great majority of our participants (almost $70 \%$ ) had pets or livestock, and some reported that they had difficulties in locating and securing their animals in time to evacuate, or were unaware of the danger and were unable to return home to gather their animals in time. In addition to providing advanced warnings in line with recommendation \#3, communities could assist pet and livestock owners by identifying and planning measures that assist locals in evacuating with their animals. For example, preparing and providing in advance the locations of public shelters that accept pets and larger animals.

\section{* Providing after-event recovery and trauma assistance}

While our participants mainly focused on their evacuation experience and not recovery after the event, it was clear from comments that the fire had a profound impact on many individuals that lingers to this day, especially those who lost their homes or loved ones or experienced a dangerous evacuation process. As a broader recommendation, it is suggested that communities consider providing after-event consoling and trauma support resources to those who survive wildfire events, including members of the public and the emergency personnel responsible for fighting and responding to the fire.

\subsection{Limitations}

In terms of the limitations to this work, as revealed by our targeted recoding effort (see Section 2.4) it is likely that a sub-section of participants misunderstood survey instructions related to the receipt of warnings and fire cues. As all participants did not provide optional end-of-survey comments to obtain further information from (and not all comments directly referenced warnings or fire cues), it is possible that the rates of observing fire cues and warnings are still under-reported in our data. In future wildfire survey efforts, it is highly recommended that survey items are pre-tested via pilot surveys and cognitive interviews to ensure mutual understanding between researchers and participants. In addition, the development and adoption of standardized items for topics such as prior experience and preparation, receipt of warnings and environmental cues, and risk perception would enable greater comparison between research findings and help to advance wildfire and evacuation research as a whole.

It must also be noted that those who responded to our survey were not perfectly representative of Sevier County and did not include all groups impacted by the fire (e.g. tourists). More specifically, while our sample was more closely representative of Sevier County in terms of gender and race it was also potentially older and slightly more affluent, with higher rates of homeownership than the County on average (via Census data). In addition, our sampling of homeowners and long-term residents of the area, while necessary for our research focus, neglected other segments of the populations of Gatlinburg and Pigeon Forge impacted by the Chimney Tops 2 fire, namely seasonal residents and visiting tourists. Further survey work on these vulnerable populations is needed to better understand their unique information needs and evacuation circumstances during wildfires. 


\section{Conclusion}

The results of this survey of the Chimney Tops 2 fire $(\mathrm{N}=323)$ found that the majority of participants from the Gatlinburg and Pigeon Forge areas were unaware of and unexperienced with wildfire threats, including evacuation planning and procedures. In addition, only a minority of participants reported receiving official information or notices prior to evacuating, more often relying upon warnings from social sources and fire cues such as smoke, embers, and flames to make their decision. The great majority of participants $(86.7 \%)$ eventually evacuated from the fire, with many describing a last-minute evacuation process.

A main recommendation from this work is to improve local awareness of wildfire threats and preparation for wildfire evacuations processes. This could be accomplished via targeted public outreach and education campaigns to both residents and visitors about local wildfire threats and evacuation procedures and by providing assistance in creating family evacuation plans, and potentially conducting community evacuation drills.

Another main finding from these results is the importance of the receipt of clear and timely official warnings. In addition to investing in a diversity of methods to communicate real-time alerts (and identifying and sharing back-up options with the public, for example in the event of extended power outages), we recommend that effective and clear warning messages are constructed in line with the latest communication research [21], [23], [24].

Other main recommendations include identifying and using trigger buffers for WUI communities during evacuation planning [22] and conducting advanced planning to identify and focus assistance on vulnerable populations (e.g., those with mobility impairments, fewer financial resources, or those in isolated locations) and those with animals to improve evacuation rates and safety. Lastly, due to the emotional nature of many comments shared in our survey, it is recommended more broadly that trauma assistance be provided to both first responders and members of the public involved in wildfire events as a part of recovery assistance.

\section{Acknowledgements}

The authors would like to thank Eric Link, Jiann Yang, and Nelson Bryner of NIST's Fire Research Division and Dr. Kristina Slagle of The Ohio State University for a comprehensive review of the document before publication.

We would also like to thank the residents of Sevier County, TN who took the time to fill out our survey and provide their experiences for our study. 


\section{References}

[1] Liu Y, Stanturf J, Goodrick S (2010) Trends in global wildfire potential in a changing climate. Forest Ecology and Management 259(4):685-697. https://doi.org/10.1016/j.foreco.2009.09.002

[2] IPPC (2007) Climate Change 2007: impacts, adaptation and vulnerability: contribution of Working Group II to the fourth assessment report of the Intergovernmental Panel. (Cambridge University Press, Cambridge, UK). https://doi.org/10.1256/004316502320517344

[3] Theobald DM, Romme WH (2007) Expansion of the US wildland - urban interface. Landscape and Urban Planning 83:340-354. https://doi.org/10.1016/j.landurbplan.2007.06.002

[4] Radeloff VC, Mckeefry J. E, Hammer RB, Stewart SI, Fried JS, Holcomb SS (2005) The Wildland-Urban Interface in the United States. Ecological Applications 15(3):799-805.

[5] McCaffrey S, Wilson R, Konar A (2018) Should I Stay or Should I Go Now? Or Should I Wait and See? Influences on Wildfire Evacuation Decisions. Risk Analysis 38(7):1390-1404. https://doi.org/10.1111/risa.12944

[6] Strahan KW, Whittaker J, Handmer J (2019) Predicting self-evacuation in Australian bushfire. Environmental Hazards 18(2):146-172. https://doi.org/10.1080/17477891.2018.1512468

[7] Folk LH, Kuligowski ED, Gwynne SMV, Gales JA (2019) A Provisional Conceptual Model of Human Behavior in Response to Wildland-Urban Interface Fires. Fire Technology 55(5):1619-1647. https://doi.org/10.1007/s10694-019-00821-z

[8] McLennan J, Elliott G, Omodei M (2012) Householder decision-making under imminent wildfire threat: stay and defend or leave? International Journal of Wildland Fire 21(7):915-925.

[9] Mozumder P, Raheem N, Talberth J, Berrens RP (2008) Investigating intended evacuation from wildfires in the wildland-urban interface: Application of a bivariate probit model. Forest Policy and Economics 10(6):415-423. https://doi.org/10.1016/j.forpol.2008.02.002

[10] Strawderman L, Salehi A, Babski-Reeves K, Thornton-Neaves T, Cosby A (2012) Reverse 911 as a complementary evacuation warning system. Natural hazards review 13(1):65-73.

[11] Guthrie V, Finucane M, Keith P, Stinnett D, Assessment M, Report T, Systems W, Science C, Board T, Engineering D, Sciences P, Academies N, Guthrie V, Finucane M, Keith P, Stinnett D, National Park Service, Comfort L, Soga K, Stacey M, Mcelwee M, Ecosse C, Dressler J, Zhao B, Baer RD, Weller SC, Roberts C (2017) After Action Review of the Chimney Tops 2 Firestorm. City of Gatlinburg, Tennessee (National Academies Press). https://doi.org/10.17730/0018-7259.78.2.133 
[12] National Park Service (2017) Chimney Tops 2 Fire Review Individual Fire Review Report. Available at https://www.wildfirelessons.net/orphans/viewincident?DocumentKey=5bfa19b8-ca1e4f4a-882f-9dad173ec28c

[13] Sorensen JH, Sorensen B V., Smith A, Williams Z (2009) Results of An Investigation of the Effectiveness of Using Reverse Telephone Emergency Warning Systems in the October 2007 San Diego Wildfires. (Oak Ridge, Tennessee).

[14] Strahan K, Whittaker J, Handmer J (2018) Self-evacuation archetypes in Australian bushfire. International Journal of Disaster Risk Reduction 27:307-316.

[15] Sorensen JH, Mileti DS (2018) Warning issuance, diffusion, and public protective action initiation during the Febuary 2017 Oroville Dam event. (Davis, California).

[16] Braun V, Clarke V (2006) Using thematic analysis in psychology. Qualitative research in psychology 3(2):77-101.

[17] McLennan J, Paton D, Beatson R (2015) Psychological differences between southeastern Australian householders' who intend to leave if threatened by a wildfire and those who intend to stay and defend. International Journal of Disaster Risk Reduction 11(March):35-46. https://doi.org/10.1016/j.ijdrr.2014.11.008

[18] Paveglio T, Prato T, Dalenberg D, Venn T (2014) Understanding evacuation preferences and wildfire mitigations among Northwest Montana residents. International Journal of Wildland Fire 23(3):435-444.

[19] Lindell MK, Perry RW (2012) The Protective Action Decision Model: Theoretical Modifications and Additional Evidence. Risk Analysis 32(4):616-632. https://doi.org/10.1111/j.1539-6924.2011.01647.x

[20] Witte K (1992) Putting the fear back into fear appeals: The extended parallel process model. Communications Monographs 59(4):329-349.

[21] Sutton J, Kuligowski ED (2019) Alerts and warnings on short messaging channels: guidance from an expert panel process. Natural Hazards Review 20(2).

[22] Cova TJ, Dennison PE, Li D, Drews FA, Siebeneck LK, Lindell MK (2017) Warning Triggers in Environmental Hazards: Who Should Be Warned to Do What and When? Risk Analysis 37(4):601-611. https://doi.org/10.1111/risa.12651

[23] Sorensen JH (2000) HAZARD WARNING SYSTEMS:REVIEW OF 20 YEARS OF PROGRESS. Natural Hazards Review. https://doi.org/10.1061/(ASCE)15276988(2000)1

[24] Sciences NA of (2018) Emergency Alert and Warning Systems: Current Knowledge and Future Research Directions (National Academies Press). https://doi.org/10.17226/24935 


\section{APPENDIX A: Survey Instrument}

\section{Chimney Tops 2 Fire Public Survey - Web/Phone}

Q1. As head of household, were you at home or in the area when the Chimney Tops 2 fire occurred in Sevier County in November, 2016?

$$
1=\mathrm{YES} \quad 2=\mathrm{NO} \quad \text { Other, please explain }
$$

If NO, close the survey; Write or say: "Thank you for your time!"

\section{Q2-Q6 relate to your understanding and actions before the Chimney Tops 2 fire.}

Q2. Before the Chimney Tops 2 fire, did you know that wildfires could be a problem in your community?

$1=$ Yes

$2=$ No

$3=$ Other, please explain

Q3. Before the Chimney Tops 2 fire, how would you have described the possibility that a wildfire would threaten your property, on a scale from 1 to 5, where 1 signifies "no possibility at all" and 5 signifies "a very good possibility"? (Select only one) *"Property" is defined here as the residence/home and surrounding land.

\begin{tabular}{|c|c|c|}
\hline $\begin{array}{l}\text { No possibility at all } \\
\text { (that a wildfire would } \\
\text { threaten my property) }\end{array}$ & & $\begin{array}{l}\text { Very good possibility } \\
\text { (that a wildfire would } \\
\text { threaten my property) }\end{array}$ \\
\hline 2 & 3 & 5 \\
\hline
\end{tabular}

Q4. Prior to the Chimney Tops 2 fire, had you or others (e.g., family, friends, businesses) taken any measures to protect your residence from wildfires? (Select all that apply)

$1=$ No measures were taken

$2=$ Cleared/removed fuel sources from property

$3=$ Moved fuel sources (e.g., woodpiles, gazebos, mulch/combustible ground cover, etc.) further away from house (but still on property)

$4=$ Installed sprinkler system (or other fire protection system) on or nearby house

$5=$ Modified residential structure

$6=$ Other, please explain

99= I don't know / don't remember 
Q5. Did you have a household emergency plan for wildfires in place before the Chimney Tops 2 fire?

$$
\begin{aligned}
1= & \text { Yes (Go to Q6) } \\
2= & \text { No (Go to Q7) } \\
& 99=\text { I don't know / don't remember }
\end{aligned}
$$

Q6. If yes, what was the ultimate goal of this household emergency plan? (Select only one)

$$
\begin{aligned}
& 1=\text { The plan was for my family/me to evacuate (leave and travel to a different/safer } \\
& \text { place) before the fire spread to my house } \\
& 2=\text { The plan was for my family/me to stay in place } \\
& 3=\text { Other, please explain } \\
& \quad 99=\text { I don't know / don't remember }
\end{aligned}
$$

Q7. Before the Chimney Tops 2 fire, how many times in the past 10 years (decade) did you evacuate your home/neighborhood/workplace (or other location) because of a wildfire? (Select only one)

Here, "evacuate" means to leave and travel to a different/safer place

$1=1=0$ times (I never evacuated before the Chimney Tops 2 fire)

$2=1$ time

$3=2-3$ times

$4=4-5$ times

$5=6+$ times

99= I don't know / don't remember

Q8-Q9 relate to your home or place of residence at the time of the 2016 Chimney Top 2 fire (November 2016).

Q8. How long had you lived at that residence? (Select only one)

$$
\begin{aligned}
1= & \text { Less than } 1 \text { year } \\
2= & 1-2 \text { years } \\
3= & 3-4 \text { years } \\
4= & 5-10 \text { years } \\
5= & 10+\text { years } \\
& 99=\text { I don't know } / \text { don't remember }
\end{aligned}
$$

Q9. Did you own or rent that residence? (Select only one)

$$
\begin{aligned}
1= & \text { Rent } \\
2= & \text { Own } \\
3= & \text { Other (Specify: } \\
& 99=\text { I don't know / don't remember }
\end{aligned}
$$


The next set of questions asks about things in the time period between when the Chimney Tops 2 fire was first detected in the Great Smoke Mountains on Wednesday, November 23, 2016 until it spread into Sevier County on Monday, November 28, 2016.

Q10. In this time period, did you receive any warnings about a wildfire occurring that could threaten your town/city or residential area?

Note: A warning includes any information (official or unofficial) from the government, media, or personal contacts such as friends, relatives or co-workers.

$1=$ Yes $($ Go to $\mathrm{Q} 11)$

$2=$ No $($ Go to Q34)

Q11. If yes, think back to that very first warning your received, how would you characterize this first warning? (Select only one)

$1=$ Official (or mandatory) order to evacuate

$2=$ Recommendation (or voluntary order) to evacuate

$3=$ Informational only

$4=$ Other (Specify:

99= I don't know / don't remember

Q12. What was the content of the first warning? (Select all that apply)

$1=$ Information about the wildfire's location

$2=$ Information about wildfire's severity

$3=$ Information about the wildfire's expected time of arrival at your location

$4=$ Information about available time for evacuation

$5=$ Information about what protective actions to take

$6=$ Information on the status of evacuation routes from the community

$7=$ Other (Specify:

99= I don't know / don't remember

Q13. How was this first warning communicated to you? (Select all that apply)

$1=$ Telephone (landline or cell phone) with a recorded message

$2=$ Telephone (landline or cell phone) with a live person

$3=$ Text message - on a mobile communication device such as a cell phone

$4=$ Internet - an email

$5=$ Internet - social media, such as Twitter or Facebook

$6=$ Internet - a website (including streaming TV, Radio)

$7=$ Face-to-face (in-person)

$8=$ A loudspeaker or public address system

$9=$ Television

$10=$ Radio

$11=$ Tone alert national weather service radio (NOAA Weather Radio)

$12=$ Outdoor warning siren

13 = Other (Specify:

99= I don't know / don't remember 
Q14. Still thinking about that first warning, who was that warning from? (Select all that apply)

$1=$ Police or fire department

$2=$ Sheriff's office

$3=$ Emergency management agency

$4=$ Governor's office

$5=$ Federal agency (e.g., National Weather Service or U.S. Forest Service)

$6=$ Family member or other relative

$7=$ Neighbor or friend

$8=$ Coworker

$9=\mathrm{TV}$, radio, or internet broadcaster

$10=$ Other (Specify:

99= I don't know / don't remember

Q15. Where were you when you received this first warning? (Select one only)

$1=$ At home

$2=$ At a relative's or friend's place

$3=$ At work

$4=$ In transit - e.g., in a vehicle, public transit, biking, walking, etc.

$5=$ Engaged in an indoor activity, outside of home or work (e.g., shopping)

$6=$ Engaged in an outdoor activity, away from home or work (e.g., sports)

$7=$ Other (Specify:

99= I don't know / don't remember

Q16. Please provide the ZIP code that best describes where you were when you received your first warning? (enter 5-digit ZIP code in the box provided)

INPUT: Zip code for the location

Q17. What day did you receive your first warning? Please indicate the date as accurately as possible. Date: (Month/Day/Year)

Q18. What time of day did you receive your first warning? Please indicate the time as accurately as possible.

Select one: Morning (from 12:01 am to 11:59 am); Afternoon (from 12:00 pm to 5:59 pm); Evening (from $6 \mathrm{pm}$ to $11: 59 \mathrm{pm}$ )

\section{The following two questions ask about what you thought when you received your first warning.}

Q19. After receiving the first warning, how much would you say you believed each of the following things on a scale of 1 to 5 where 1 represents "did not believe" and 5 represents "fully believed?" (Select a number for each statement)

\begin{tabular}{|c|c|c|c|c|c|}
\hline & $\begin{array}{l}\text { Did not } \\
\text { believe }\end{array}$ & & & & $\begin{array}{l}\text { Fully } \\
\text { elieved }\end{array}$ \\
\hline A. The fire would spread to my neighborhood & 1 & 2 & 3 & 4 & 5 \\
\hline $\begin{array}{l}\text { B. My neighborhood would be damaged/destroyed by } \\
\text { fire }\end{array}$ & 1 & 2 & 3 & 4 & 5 \\
\hline C. My home would be damaged/destroyed by fire & 1 & 2 & 3 & 4 & 5 \\
\hline
\end{tabular}


Q20. After receiving the first warning, how much would you say you agreed with each of the following statements on a scale of 1 to 5 where 1 represents "not likely" and 5 represents "extremely likely?" (Select a number for each statement)

\begin{tabular}{|lllllc|}
\hline & $\begin{array}{l}\text { Not } \\
\text { likely }\end{array}$ & & & \multicolumn{2}{c|}{$\begin{array}{c}\text { Extremely } \\
\text { likely }\end{array}$} \\
A. I might become injured & $\frac{1}{1}$ & 2 & 3 & 4 & 5 \\
B. Other people/pets/livestock might become injured & 1 & 2 & 3 & 4 & 5 \\
C. I might die & 1 & 2 & 3 & 4 & 5 \\
D. Other people/pets/livestock might die & 1 & 2 & 3 & 4 & 5 \\
\hline
\end{tabular}

Q21. What was your immediate reaction to the first warning? (Select only one)

$1=$ No reaction; I continued my activities

$2=$ I waited for more information

$3=$ I tried to find more information

$4=$ I started preparing to act, and then waited for further information

$5=\mathrm{I}$ took action immediately (e.g., evacuated/left the location, defended my property, took shelter, etc.)

99=I don't know / don't remember

Q22. After receiving your first warning, but before you either began your evacuation or decided not to evacuate, did you receive or seek out any additional warnings about a fire occurring that could threaten your town/city or residential area?

(Reminder: warnings include any information [official or unofficial] from the government, media, or personal contacts such as friends, relatives or co-workers)

$1=$ Yes $($ Go to $\mathrm{Q} 23)$

$2=$ No (Go to Q27)

Q23. How would you characterize these additional warnings? (Select all that apply)

$1=$ Official (or mandatory) order to evacuate

$2=$ Recommendation (or voluntary order) to evacuate

$3=$ Informational only

$4=$ Other (Specify:

99= I don't know / don't remember

Q24. What was the content of the additional warnings? (Select all that apply)

$1=$ Information about the wildfire's location

$2=$ Information about wildfire's severity

$3=$ Information about the wildfire's time of arrival at your location

$4=$ Information about available time for evacuation

$5=$ Information about what protective actions to take

$6=$ Information on the status of evacuation routes from the community

$7=$ Other (Specify:

99=I don't know / don't remember 
Q25. Who were these additional warnings from? (Select all that apply)

$1=$ Police or fire department

$2=$ Sheriff's office

$3=$ Emergency management agency

$4=$ Governor's office

$5=$ Federal agency (e.g., National Weather Service or U.S. Forest Service)

$6=$ Family member or other relative

$7=$ Neighbor or friend

$8=$ Coworker

$9=\mathrm{TV}$, radio, or internet broadcaster

$10=$ Other (Specify:

99=I don't know / don't remember

Q26. How did you receive these additional warnings? (Select all that apply)

$1=$ Telephone (landline or cell phone) with a recorded message

$2=$ Telephone (landline or cell phone) with a live person

$3=$ Text message - on a mobile communication device such as a cell phone

$4=$ Internet - an email

$5=$ Internet - social media, such as Twitter or Facebook

$6=$ Internet - a website (including streaming TV, Radio)

$7=$ Face-to-face (in-person)

$8=$ A loudspeaker or public address system

$9=$ Television

$10=$ Radio

$11=$ Tone alert national weather service radio (NOAA Weather Radio)

$12=$ Outdoor warning siren

$13=$ Other (Specify:

99=I don't know / don't remember

Q27. Before you either began your evacuation or decided not to evacuate, did you receive any information about the Chimney Tops 2 fire from the fire itself, e.g., seeing, hearing, feeling, or smelling the fire such as flames, smoke, embers, etc.?

$$
\begin{aligned}
& 1=\text { Yes (Go to Q28) } \\
& 2=\text { No (Go to Q43) }
\end{aligned}
$$

Q28. What did you see, hear, feel or smell from the fire (also known as "fire cues")? (Select all that apply)

$1=$ Flames

2 Embers (i.e., small or larger pieces of burning or glowing materials flying past your property or landing on your property)

$3=$ Smoke

$4=$ Winds

$5=$ Heat

$6=$ Other

Q29. What day did you receive these cues? Please indicate the date as accurately as possible. Date: (Month/Day/Year) 
Q30. What time of day did you receive these cues? Please indicate the time of day as accurately as possible.

Select one: Morning (from 12:01 am to 11:59 am); Afternoon (from 12:00 pm to 5:59 pm); Evening (from $6 \mathrm{pm}$ to $11: 59 \mathrm{pm}$ )

Q31. After receiving those fire cues, how much would you say you believed each of the following things on a scale of 1 to 5 where 1 represents "did not believe" and 5 represents "fully believed?" (Select a number for each statement)

\begin{tabular}{|c|c|c|c|c|c|}
\hline & $\begin{array}{l}\text { Did not } \\
\text { believe }\end{array}$ & & & & $\begin{array}{l}\text { Fully } \\
\text { elieved }\end{array}$ \\
\hline The fire would spread to my neighborhood & 1 & 2 & 3 & 4 & 5 \\
\hline $\begin{array}{l}\text { My neighborhood would be damaged/destroyed by } \\
\text { fire }\end{array}$ & 1 & 2 & 3 & 4 & 5 \\
\hline My home would be damaged/destroyed by fire & 1 & 2 & 3 & 4 & 5 \\
\hline
\end{tabular}

Q32. After receiving those fire cues, how much would you say you agreed with each of the following statements on a scale of 1 to 5 where 1 represents "not likely" and 5 represents "extremely likely?" (Select a number for each statement)

\begin{tabular}{|c|c|c|c|c|c|}
\hline & $\begin{array}{l}\text { Not } \\
\text { likely }\end{array}$ & & & & $\begin{array}{l}\text { tremely } \\
\text { likely }\end{array}$ \\
\hline A I might become injured & 1 & 2 & 3 & 4 & 5 \\
\hline B. Other people/pets/livestock might become injured & 1 & 2 & 3 & 4 & 5 \\
\hline C. I might die & 1 & 2 & 3 & 4 & 5 \\
\hline D. Other people/pets/livestock might die & 1 & 2 & 3 & 4 & 5 \\
\hline
\end{tabular}

Q33. What was your immediate reaction to these fire cues? (Select only one)

$1=$ No reaction; I continued my activities

$2=$ I waited for more information

$3=\mathrm{I}$ tried to find more information

$4=$ I started preparing to act, and then waited for further information

$5=$ I took action immediately (e.g., evacuated/left the location, defended my property, took shelter, etc.)

99=I don't know / don't remember

(After any response to this question, Go to Q43)

Q34. If no, did you receive any information about the Chimney Tops 2 fire from the fire itself before you either began your evacuation or decided not to evacuate.

Information from the fire can include seeing, hearing, feeling, or smelling the fire such as flames, smoke, embers, etc.?

$1=$ Yes (Go to Q35)

$2=$ No (Go to Q43) 
Q35. If yes, what did you see, hear, feel or smell from the fire (also known as "fire cues")? (Select all that apply)

$1=$ Flames

$2=$ Embers (i.e., small or larger pieces of burning or glowing materials flying past your property or landing on your property)

$3=$ Smoke

$4=$ Winds

$5=$ Heat

$6=$ Other

Q36. Where were you when you received those fire cues? (Select only one)

$1=$ At home

$2=$ At a relative's or friend's place

$3=$ At work

$4=$ In transit - e.g., in a vehicle, public transit, biking, walking, etc.

$5=$ Engaged in an indoor activity, outside of home or work (e.g., shopping)

$6=$ Engaged in an outdoor activity, away from home or work (e.g., sports)

$7=$ Other (Specify:

99=I don't know / don't remember

Q37. Please provide the ZIP code that best describes where you were when you received those fire cues? (enter 5-digit ZIP code in the box provided)

INPUT: Zip code for the location

Q38. What day did you perceive those fire cues? Please indicate the date as accurately as possible.

Date: (Month/Day/Year)

Q39. What time of day did you perceive those fire cues? Please indicate the time as accurately as possible.

Select one: Morning (from 12:01 am to 11:59 am); Afternoon (from 12:00 pm to 5:59 pm);

Evening (from $6 \mathrm{pm}$ to $11: 59 \mathrm{pm}$ )

Q40. After receiving those fire cues, how much would you say you believed each of the following things on a scale of 1 to 5 where 1 represents "did not believe" and 5 represents "fully believed?" (Select a number for each statement)

\begin{tabular}{|c|c|c|c|c|c|}
\hline & $\begin{array}{l}\text { Did not } \\
\text { believe }\end{array}$ & & & & $\begin{array}{l}\text { Fully } \\
\text { elieved }\end{array}$ \\
\hline The fire would spread to my neighborhood & 1 & 2 & 3 & 4 & 5 \\
\hline $\begin{array}{l}\text { My neighborhood would be damaged/destroyed by } \\
\text { fire }\end{array}$ & 1 & 2 & 3 & 4 & 5 \\
\hline C. My home would be damaged/destroyed by fire & 1 & 2 & 3 & 4 & 5 \\
\hline
\end{tabular}


Q41. After receiving those fire cues, how much would you say you agreed with each of the following statements on a scale of 1 to 5 where 1 represents "not likely" and 5 represents "extremely likely?" (Select a number for each statement)

\begin{tabular}{|c|c|c|c|c|c|}
\hline & $\begin{array}{l}\text { Not } \\
\text { likely }\end{array}$ & & & & $\begin{array}{l}\text { tremely } \\
\text { likely }\end{array}$ \\
\hline A I might become injured & 1 & 2 & 3 & 4 & 5 \\
\hline B. Other people/pets/livestock might become injured & 1 & 2 & 3 & 4 & 5 \\
\hline C. I might die & 1 & 2 & 3 & 4 & 5 \\
\hline D. Other people/pets/livestock might die & 1 & 2 & 3 & 4 & 5 \\
\hline
\end{tabular}

Q42. What was your immediate reaction to the fire cues? (Select only one)

$1=$ No reaction; I continued my activities

$2=\mathrm{I}$ waited for more information

$3=\mathrm{I}$ tried to find more information

$4=$ I started preparing to act, and then waited for further information

$5=\mathrm{I}$ took action immediately (e.g., evacuated/left the location, defended my property, took shelter, etc.)

99=I don't know / don't remember

Q43. Before you either began your evacuation or decided not to evacuate, how many total warnings did you receive about the Chimney Tops 2 fire that you would classify as "official or mandatory evacuation warnings"? (Select only one)

$1=0$ (none)

$2=1$

$3=2$

$4=3$

$5=4+$

99=I don't know / don't remember

Q44. Who do you consider the most credible source of information about wildfire events? (Select only one)

$1=$ Police or fire department

$2=$ Sheriff's office

$3=$ Emergency management agency

$4=$ Governor's office

$5=$ Federal agency (e.g., National Weather Service or U.S. Forest Service)

$6=$ Family member or other relative

$7=$ Neighbor or friend

$8=$ Coworker

$9=\mathrm{TV}$, radio, or internet broadcaster

$10=$ Other (Specify:

99= I don't know / don't remember 
Now, we are discussing the decisions you made in response to the Chimney Tops 2 fire.

Q45. In response to the Chimney Tops 2 fire, what did you decide to do? (Select only one) $1=\mathrm{I}$ decided to stay in place $2=$ I decided to evacuate (leave and travel to a different/safer place)

Q46. What day did you make this decision? Please indicate the date as accurately as possible. Date: (Month/Day/Year)

Q47. What time of day did you make this decision? Please indicate the time of day as accurately as possible.

Select one: Morning (from 12:01 am to 11:59 am); Afternoon (from 12:00 pm to 5:59 pm); Evening (from $6 \mathrm{pm}$ to $11: 59 \mathrm{pm}$ )

Q48. At that moment you decided what to do, how much would you say you agreed with each of the following statements on a scale of 1 to 5 where 1 represents "not likely" and 5 represents "extremely likely?" (Select a number for each statement)

\begin{tabular}{|lllllcc|}
\hline & \multicolumn{1}{l}{ Not } & & & Extremely \\
& \multicolumn{1}{l}{ likely } & & & & $\underline{\text { likely }}$ \\
A. I might become injured & 1 & 2 & 3 & 4 & 5 \\
B. Other people/pets/livestock might become injured & 1 & 2 & 3 & 4 & 5 \\
C. I might die & 1 & 2 & 3 & 4 & 5 \\
D. Other people/pets/livestock might die & 1 & 2 & 3 & 4 & 5 \\
\hline
\end{tabular}

Q49. Which of the following best describes how you made this decision? (Select only one)

$1=$ I made the decision (by myself)

$2=$ My family made the decision together

$3=$ My friends/neighbors made the decision together

$4=$ My family/I followed a previously developed plan

$5=\mathrm{I}$ decided to follow what others were doing around me

$6=\mathrm{I}$ decided to follow instructions by an authority

$7=$ Other

99=I don't know / don't remember

\section{Now, we are discussing your actual response to the Chimney Tops 2 fire.}

Q50. In Question 45, we asked about what you decided to do. Here, we want you to think about which of the following responses best describes what you eventually DID in response to the Chimney Tops 2 fire. (Select only one)

$1=\mathrm{I}$ evacuated (left for a safer place) (Go to Q51)

$2=$ I stayed in place (Go to Q55) 
Q51. What were the main reasons that you eventually left/evacuated? (Select all that apply)

$1=$ Seeing, hearing, smelling cues from the fire (flames, embers, smoke, winds, heat)

$2=$ Observing others evacuating (from TV/radio, social media)

$3=$ Observing others evacuating (in person - seeing them in my neighborhood)

$4=$ Was afraid/felt danger for myself

$5=$ Was afraid/felt danger for my family/friends

$6=$ Was afraid for my pets/livestock (or other farm animals)

$7=$ Information about the fire (location, intensity, etc.)

$8=$ My property caught fire

$9=$ I was being overcome by the effects of heat/smoke

$10=$ Police, fire or other emergency official(s) advised me to leave

$11=$ Police, fire or other emergency official(s) ordered me to leave

$12=$ My family, friends or neighbors, etc. advised me to leave

$13=$ My family, friends or neighbors, etc. ordered me to leave

$14=$ Other

99=I don't know / don't remember

Q52. Between the time you received your first warning or fire cue and the time you evacuated, did you do any of the following before leaving? (Select all that apply)

$1=$ Reunite with family members

2 =Reunite with others outside of family (e.g., friends, neighbors, coworkers)

$3=$ Prepare family members and/or self (getting them dressed, use the bathroom)

$4=$ Reunite with or attend to pets/livestock (or other farm animals)

$5=$ Secure my home (e.g., prepared house by turning off gas, turning off air conditioning, shut windows)

$6=$ Perform preparation actions (e.g., tidied up garden/outdoors, put water on the house/vegetation/landscape)

$7=$ Secure my business

$8=$ Pack items to take with me / load vehicle

$9=$ Tell others what I was doing

$10=$ Tell others about the fire/ what was going on/ what they should do

$11=$ Inquire (ask) about what others were doing (or going to do)

$12=$ Plan an evacuation route (e.g., travel directions)

$13=$ Identify / secure an evacuation destination

$14=$ Help others prepare

$15=$ Other $($ SPECIFY

$98=\mathrm{I}$ did not do anything after deciding to respond

99= I don't know / don't recall

Q53. What day did you actually leave (evacuate)? Please indicate the date as accurately as possible. Date: (Month/Day/Year)

Q54. What time of day did you actually leave (evacuate)? Please indicate the date as accurately as possible.

Select one: Morning (from 12:01 am to 11:59 am); Afternoon (from 12:00 pm to 5:59 pm); Evening (from $6 \mathrm{pm}$ to $11: 59 \mathrm{pm}$ )

(After any response to this question, Go to Q56) 
Q55. If you did not evacuate, why didn't you leave? (Select all that apply)

$1=\mathrm{I}$ was not in an area ordered to evacuate

$2=\mathrm{I}$ did not believe that I was in an area at risk of wildfires

$3=$ I did not receive any evacuation messages or warnings

$4=$ I did not think that there would be a fire

$5=\mathrm{I}$ did not know anything about the fire

$6=$ I stayed behind to do my job

$7=$ I observed others staying behind (from TV/radio, social media)

$8=$ I observed others staying behind (in person - seeing them in the neighborhood)

$9=$ I stayed behind to protect (or defend) my property

$10=$ I stayed behind to take care of pets/livestock (or other farm animals)

$11=$ I stayed behind to take care of a person (or persons) unable to evacuate

$12=$ I did not have the resources, for example, money or a vehicle

$13=$ I was physically unable to evacuate

$14=$ It was too late to leave and/or it was too dangerous to evacuate

$15=$ I thought that it was safer to stay in place

$16=$ Other (Specify:

99= I don't know / don't remember

\section{The last set of questions is about you. Answers to these questions will help us learn how different types of people receive and respond to wildfires.}

Q56. Do you consider yourself male, female, or other? (Select only one). You may skip this question, if you prefer not to answer.

$$
\begin{aligned}
& 1=\text { Male } \\
& 2=\text { Female } \\
& 3=\text { Other }
\end{aligned}
$$

Q57. Which of the following racial/ethnic groups best describes you? (Select one or more). You may skip this question, if you prefer not to answer.

$1=$ Hispanic or Latino

$2=$ Black or African American

$3=$ Asian

$4=$ Native Hawaiian or other Pacific Islander

$5=$ American Indian or Alaskan Native

$6=$ White

Q58. How old are you? (Please choose from one of the following age ranges)

$1=18-24$ years old

$2=25-34$ years old

$3=35-44$ years old

$4=45-54$ years old

$5=55-64$ years old

$6=65-74$ years old

$7=75$ years or older

99=Prefer not to answer 
Q59. What is the highest level of education you have completed? (Select only one)

$1=$ Less than high school diploma

$2=$ High school diploma or equivalent

$3=$ Some college but no degree

$4=$ Associate degree

$5=$ Bachelor degree

$6=$ Graduate degree

$99=$ Prefer not to answer

Q60. Thinking of all the people in your household, what was the total household income, including your own income, from all sources in 2016? (Select only one)

$$
\begin{aligned}
1= & \text { Less than } \$ 15,000 \\
2= & \$ 15,000 \text { to } \$ 24,999 \\
3= & \$ 25,000 \text { to } \$ 34,999 \\
4= & \$ 35,000 \text { to } \$ 49,999 \\
5= & \$ 50,000 \text { to } \$ 74,999 \\
6= & \$ 75,000 \text { to } \$ 99,999 \\
7= & \$ 100,000 \text { to } \$ 149,999 \\
8= & \$ 150,000 \text { to } \$ 199,999 \\
9= & \$ 200,000 \text { or more } \\
& 99=\text { Prefer not to answer }
\end{aligned}
$$

Q61. Which of the following categories best describes your employment status in 2016? (Select only one)

$1=$ Employed [including self-employed], working 1-39 hours per week

$2=$ Employed [including self-employed], working 40 or more hours per week

$3=$ Not employed

$4=$ Retired

$5=$ Disabled, not able to work

$6=$ Stay at home $\mathrm{mom} / \mathrm{dad}$

99=Prefer not to answer

Q62. How many people and pets including yourself lived in your household (or on your property) on November 28, 2016, the day the fire impacted your community? (Please provide numbers for the following; or insert numbers in the boxes, below)

Children: under 13 years old ( 0 - 12 years old)

Children: 13 years old to 17 years old

Adults (including children): 18 years old to 64 years old

Adults: 65 years old and older

Pets

Livestock/other farm animals 
Q63. Did you or someone in your household, including yourself, have a medical condition at the time of the Chimney Tops 2 fire?

Note that a medical condition can include a visual or hearing impairment, a mobility impairment, and/or pregnancy. If you prefer not to answer, you can skip this question.

$$
1=\text { Yes }
$$$$
2=\mathrm{No}
$$

(Note - the respondent should be able to skip this question if they do not wish to answer.)

(Next screen...or end with the following statement):

Thank you for your participation in this survey!

This collection of information contains Paperwork Reduction Act (PRA) requirements approved by the Office of Management and Budget (OMB). Notwithstanding any other provisions of the law, no person is required to respond to, nor shall any person be subject to a penalty for failure to comply with, a collection of information subject to the requirements of the PRA unless that collection of information displays a currently valid OMB control number. For this collection, the OMB Control number is:0693-0078 with an expiration date: July 31, 2019. Public reporting burden for this collection is estimated to be 20 minutes per survey, including the time for reviewing instructions, searching existing data sources, gathering and maintaining the data needed and completing and reviewing the collection of information. Send comments regarding this burden estimate or any aspect of this collection of information, including suggestions for reducing this burden, to the National Institute of Standards and Technology, Attn: Dr. Erica Kuligowski, NIST, 100 Bureau Drive, MS 8662, Gaithersburg, MD 20899-8662, telephone 301-975-2309, or via email:erica.kuligowski@nist.gov. 